\title{
Global economic and environmental outcomes of the Paris Agreement is $^{2}$
}

\author{
Weifeng Liu ${ }^{\mathrm{a}, *}$, Warwick J. McKibbin ${ }^{\mathrm{a}, \mathrm{b}}$, Adele C. Morris ${ }^{\mathrm{b}}$, Peter J. Wilcoxen ${ }^{\mathrm{b}, \mathrm{c}}$ \\ a Crawford School of Public Policy, The Australian National University, Canberra, ACT 2601, Australia \\ b The Brookings Institution, Washington, DC 20036, USA \\ c The Maxwell School, Syracuse University, Syracuse, NY 13244, USA
}

\section{A R T I C L E I N F O}

\section{Article history:}

Received 19 January 2019

Received in revised form 10 June 2020

Accepted 18 June 2020

Available online 27 June 2020

\section{Keywords:}

Climate change

Paris Agreement

Global macroeconomic modeling

G-cubed

Carbon taxes

Carbon pricing

\section{JEL classification:}

C54

F17

F41

F47

Q43

Q54

\begin{abstract}
A B S T R A C T
In this paper, we use a ten-region model of the world economy to analyze the economic and environmental outcomes that are likely to result from the Paris Climate Agreement. To construct our modeling scenario, we first convert the Agreement's disparate Nationally Determined Contribution (NDC) pledges into equivalent reductions in $\mathrm{CO} 2$ emissions relative to a baseline scenario without the Agreement. We then model the Agreement by solving for a $\mathrm{CO} 2$ price path in each region that would gradually fulfill the region's NDC pledge by its target date. The resulting paths are quite different across regions, indicating significant differences in marginal abatement costs. We also find that if all regions achieve their NDCs, the Agreement significantly reduces $\mathrm{CO} 2$ emissions relative to baseline. However, global emissions would not decline in absolute terms relative to 2015 levels, let alone follow a path consistent with a $2{ }^{\circ} \mathrm{C}$ stabilization scenario. We then construct additional scenarios to explore how the outcomes of the Agreement would change if particular countries (the United States, China, and Australia) were to unilaterally withdraw from it without undertaking alternative climate policies. We find that leaving the Agreement raises GDP for the country that leaves, but it also sharply reduces the domestic cobenefits the country receives as a side effect of controlling $\mathrm{CO}$. For each country we consider, the net effect of withdrawing is negative: the loss of co-benefits exceeds the gain in GDP. That is, we show that when cobenefits are considered, it is in each country's self-interest to remain in the Agreement.
\end{abstract}

(c) 2020 Elsevier B.V. All rights reserved.

\section{Introduction}

The Paris Climate Agreement (the Agreement), adopted by the Parties to the United Nations Framework Convention on Climate Change (UNFCCC) in 2015, has been signed by 197 countries and went into force in November of 2016. It is arguably the first truly global climate change agreement and aims to put the world on track to eventually stabilize greenhouse gas (GHG) emissions at a level that would avoid dangerous climate change, although the commitments made in 2015 are not enough to achieve that goal on their own.

Before and during the Paris conference, countries submitted national plans to the UNFCCC that explain what GHG or related targets they plan to achieve. Following through on these Nationally Determined Contributions (NDCs) will create a range of environmental and economic

\footnotetext{
is We gratefully acknowledge financial support from the Alcoa Foundation (Grant number 222784). The conclusions and recommendations do not reflect the views of the institutions with which the authors are affiliated. We thank Nicholas Montalbano for his research assistance.

* Corresponding author.

E-mail addresses: dr.weifeng.liu@gmail.com (W. Liu), warwick.mckibbin@anu.edu.au (W.J. McKibbin), amorris@brookings.edu (A.C. Morris), wilcoxen@maxwell.syr.edu (P.J. Wilcoxen).
}

consequences for the participants over the coming decades. This paper uses G-Cubed, a multi-country, multi-sector model of the global economy to project those outcomes. We simulate policies that would achieve the commitments of countries in each of the regions in the model and estimate how much global carbon dioxide $\left(\mathrm{CO}_{2}\right)$ emissions would fall relative to what would happen without those policies. We also estimate the economic results of the policies in each region, such as how they affect GDP growth, trade, and investment flows. These results allow us to characterize how environmentally and economically ambitious the NDCs are in both absolute terms and relative to each other.

The paper also explores how environmental and economic outcomes would change if particular countries unilaterally withdraw from the Agreement without undertaking alternative climate policies. For example, in light of the Trump Administration's announcement that the United States will withdraw from the Agreement by 2020, we run scenarios with and without participation by the United States. We also repeat the simulations with and without China, the world's largest GHG emitter, and with and without Australia, an important fossil fuel exporter.

There is an emerging literature exploring the economic impacts of the Agreement based on modeling exercises. Our contributions are 
broadly two-fold, one on the modeling framework and the other on the focus of the analysis. First, our model is different from other dynamic general equilibrium models used for examining the Agreement in several respects. The model incorporates important short-run rigidities such as adjustment costs in physical capital accumulation, wage stickiness and central bank monetary policy rules, and thus allows us to capture short- and medium-term adjustment impacts which cannot be analyzed using long-term models. The model also has a full menu of financial assets, the valuation of which in the face of policy changes can have impacts on the real economy in the short run. The electricity sectors in each country and region are highly disaggregated and consist of different electricity generation technologies, which makes the model particularly suitable for analyzing energy and climate policies. The model also incorporates heterogeneity in households and firms by modeling households and firms following a mix of both forwardlooking and backward-looking behavior. This deviation from fully forward-looking optimizing behavior creates additional dynamics compared to other representative agent models. These model features are discussed in more detail in Section $4{ }^{1}$

Second, we examine not only the economic impacts of the Agreement but also the environmental outcomes, particularly the cobenefits from climate policies. In addition to the scenario with all regions participating in the Agreement, we also investigate the results of unilateral withdrawal by key countries. We find that when the cobenefits are included in evaluating the Agreement, all countries are better off staying in the Agreement than exiting unilaterally.

The paper proceeds as follows. Section 2 outlines the NDCs of the regions in the model and presents our equivalent $\mathrm{CO}_{2}$ targets. Section 3 summarizes other studies of the Agreement with coverage divided into two sections: global studies and national studies of China and the United States. Section 4 presents an overview of the G-Cubed model and outlines the baseline scenario, which projects future economic and environmental outcomes without the Agreement. Section 5 presents our analysis of the Agreement in two parts. The first presents detailed results for the case when all regions participate and fulfill their NDC pledges. The second considers the emissions and macroeconomic outcomes that would occur if individual regions withdraw from the Agreement. Section 6 concludes.

\section{Representing NDCS in modeling scenarios}

The NDCs vary considerably across countries. Differences include the range of GHGs covered by targets, the sectors of the economy to which targets apply; the base year used to establish targets; the year in which the target is to be reached; and the metrics of the targets themselves. We begin our analysis by converting the NDCs to a common basis: the paths they imply for each participant's future $\mathrm{CO}_{2}$ emissions. We then aggregate the results, where needed, so that they are suitable for use with the level of geographic detail available in G-Cubed, as shown in Table 1. We follow the approach in McKibbin et al. (2011), which compared commitments in the Copenhagen Accord.

Converting NDC targets into emissions paths appropriate for the model is a complex task. In some cases, the targets are straightforward emissions levels in a particular year relative to an historical base year, but we must still specify an emissions path for the years before the target date. In other cases, such as China and India, the targets are expressed as emission intensities (i.e. emissions per unit of GDP). The calculation of emission intensities requires an estimate of projected output which can then be used to calculate the implied level of emissions. Adding to the complexity, where countries in the G-Cubed model are aggregated into regions, we must calculate a region-wide target. The calculation of region-wide targets is most difficult for the Rest of the

\footnotetext{
${ }^{1}$ In addition, Appendix $C$ examines the sensitivity of the model's results to several of these features.
}

Table 1

Regions in the G-Cubed model.

\begin{tabular}{ll}
\hline Region & Region description \\
\hline Australia & Australia \\
China & China \\
Europe & Europe \\
India & India \\
Japan & Japan \\
OPEC & Oil-exporting developing countries \\
ROECD & Rest of the OECD, i.e. Canada, New Zealand and Iceland \\
ROW & Rest of the World \\
Russia & Russian Federation \\
USA & United States \\
\hline
\end{tabular}

World (ROW) region, which amalgamates countries with emission targets, intensity targets, and no targets.

One limitation of this study is that G-Cubed only includes $\mathrm{CO}_{2}$ emissions from fossil energy combustion, not other $\mathrm{GHGs}$ or $\mathrm{CO}_{2}$ from industrial processes. Thus, to convert targets into the modeling simulations, we assume that NDC pledges to reduce broader $\mathrm{CO}_{2}$-equivalent emissions will result in proportional reductions in $\mathrm{CO}_{2}$ emissions from fossil fuels. ${ }^{2}$ For example, the United States NDC pledges a 26\% reduction in the full U.S. GHG inventory, so we simulate a $26 \%$ reduction in U.S. energy-related $\mathrm{CO}_{2}$. Thus, the results are approximate estimates of the economic adjustments under the Agreement.

Table 2 summarizes our representation of the NDCs for the regions in the model. For countries that offered alternative targets that would be more stringent under certain circumstances, such as assistance from developed countries, we model the target without such conditions (hence the term "unconditional reduction target" in column 7). For countries that offered a range of emissions targets, we chose the least stringent. Regions such as OPEC, ROECD and ROW involved significantly more analysis and require more detailed descriptions; we discuss them in Appendix A and omit them from Table 2. The reduction target column shows the proposed decline in the applicable NDC's metric from the NDC's base year to the target year. For example, India committed to a 33\% decline in all GHG emissions per unit GDP from 2005 to 2030.

Table 3 reports the $\mathrm{CO}_{2}$ emissions targets for each region as we have approximated them for the modeling scenario.

The second column of Table 3 reports the 2015 level of $\mathrm{CO}_{2}$ emissions in the region in millions of metric tons, as generated by the model. The third column is the target year of the NDC. The fourth column reports emissions in the target year under the baseline scenario, which we also refer to as the business as usual (BAU) or reference scenario. The fifth column contains the targeted level of emissions in the target year, as we have calculated it per the discussion in Appendix A. The sixth column contains the ratio of projected emissions in the baseline in the target year ( 2025 for the U.S. and 2030 for all others) relative to emissions in 2015. The emissions figure reflects the projected growth in emissions without new policies. For example, without new climate policies, the model projects Chinese $\mathrm{CO}_{2}$ emissions would grow by about $91 \%$ by the target year, and European $\mathrm{CO}_{2}$ emissions would grow by only $7 \%$.

The seventh column shows the ratio of the target to baseline emissions in the target year. This ratio puts in common terms the policy performance needed to hit the NDC targets. That is, the change in emissions in the target year relative to the emissions that would have occurred without the policies to implement the NDCs provides one measure of the economic ambition of each target. The ratios of the target to baseline emissions in column seven vary from 0.57 for Japan, reflecting the greatest percent emissions reduction relative to $\mathrm{BAU}$, to 0.90 for oil-

\footnotetext{
2 There are alternative assumptions about the relationship between $\mathrm{CO}_{2}$ emissions and GHG emissions in the literature. For example, Chen and Hafstead (2019) consider different scenarios of non- $\mathrm{CO}_{2}$ emissions projections and thus have different $\mathrm{CO}_{2}$ emissions targets given the same GHG emissions target.
} 
Table 2

NDCs for the regions in the G-Cubed model.

\begin{tabular}{|c|c|c|c|c|c|c|}
\hline Region & GHG Coverage & Sectoral coverage & Metric & NDC Base year & NDC Target year & Unconditional reduction target \\
\hline Australia & All GHGs & All sectors & Emissions & 2005 & 2030 & $-26 \%$ \\
\hline China & $\mathrm{CO}_{2}$ & Energy & Emissions per unit GDP & 2005 & 2030 & $-60 \%$ \\
\hline Europe & All GHGs & All sectors & Emissions & 1990 & 2030 & $-40 \%$ \\
\hline India & All GHGs & All sectors & Emissions per unit GDP & 2005 & 2030 & $-33 \%$ \\
\hline Japan & All GHGs & All sectors excluding terrestrial carbon & Emissions & 2013 & 2030 & $-26 \%$ \\
\hline OPEC & See Appendix & & & & & \\
\hline ROECD & See Appendix & & & & & \\
\hline ROW & See Appendix & & & & & \\
\hline Russia & All GHGs & All sectors & Emissions & 1990 & 2030 & $-25 \%$ \\
\hline USA & All GHGs & All sectors including terrestrial carbon & Emissions & 2005 & 2025 & $-26 \%$ \\
\hline
\end{tabular}

Table 3

Targeted $\mathrm{CO}_{2}$ emissions from energy use for regions.

\begin{tabular}{|c|c|c|c|c|c|c|}
\hline 1 & 2 & 3 & 4 & 5 & 6 & 7 \\
\hline Region & $\begin{array}{l}2015 \text { emissions } \\
\text { (MMt) }\end{array}$ & $\begin{array}{l}\text { Target } \\
\text { year }\end{array}$ & $\begin{array}{l}\text { Baseline emissions } \\
\text { in target year (MMt) }\end{array}$ & Target (MMt) & $\begin{array}{l}\text { Ratio of baseline emissions } \\
\text { in target year to } 2015 \text { emissions }\end{array}$ & $\begin{array}{l}\text { Ratio of target to baseline } \\
\text { emissions in target year }\end{array}$ \\
\hline Australia & 377 & 2030 & 457 & 297 & 1.21 & 0.65 \\
\hline China & 9610 & 2030 & 18,319 & 13,340 & 1.91 & 0.73 \\
\hline Europe & 3809 & 2030 & 4086 & 2540 & 1.07 & 0.62 \\
\hline India & 1982 & 2030 & 3864 & 2908 & 1.95 & 0.75 \\
\hline Japan & 1206 & 2030 & 1526 & 876 & 1.27 & 0.57 \\
\hline OPEC & 2525 & 2030 & 3550 & 3212 & 1.41 & 0.90 \\
\hline ROECD & 590 & 2030 & 742 & 456 & 1.26 & 0.61 \\
\hline ROW & 5894 & 2030 & 8780 & 7246 & 1.49 & 0.83 \\
\hline Russia & 1798 & 2030 & 1933 & 1541 & 1.08 & 0.80 \\
\hline USA & 5359 & 2025 & 5921 & 4440 & 1.10 & 0.75 \\
\hline
\end{tabular}

exporting countries. By this standard, OPEC offers a significantly less ambitious pledge than other regions. The United States is on par with China and India, and Europe and the rest of the OECD are only slightly less ambitious than Japan. However, as the modeling results will show, this measure does not fully capture the relative macroeconomic impacts of the Agreement on different countries.

In addition to the targets in Table 3, the modeling scenario must specify the policies that regions adopt to achieve their targets, and the emissions paths those policies will follow from 2015 to the target year. For simplicity, we model each G-Cubed region as achieving its emissions target by imposing prices on $\mathrm{CO}_{2}$ emissions from fossil fuel use. Revenues from the fees return to households in the region in an annual lump sum rebate. We impose linearly declining annual emissions targets and calculate the $\mathrm{CO}_{2}$ prices necessary each year to achieve them. ${ }^{3}$

\section{Other studies of the Paris Agreement}

The literature on the Agreement is enormous, so here we focus on studies like ours that use large-scale computational models. A table summarizing the relevant studies appears in Appendix B. Some were undertaken in the lead-up to the Paris negotiations to inform negotiators about proposed NDCs. Most are more recent, having been completed since the Agreement. These studies either analyze announced policies and measures or assume, as we do, illustrative policies implemented to hit particular targets. The modeling studies of the Agreement are not directly comparable with each other or with ours because: (1) they assume different targets and different policies to reach those targets; (2) they use different modeling approaches with different assumptions and model structures; or (3) they focus on different aspects of the Agreement.

\footnotetext{
3 This approach does not minimize the intertemporal cost of the emissions reductions achieved. For that, the price would need to start at a much higher value in 2020 than in our runs and then rise at the real rate of interest. Our prices start lower but rise much more quickly: typically $15 \%$ to $20 \%$ per year. A cost-minimizing approach would thus have greater reductions in the near term and smaller reductions in the long term than our policies.
}

Modeling studies include both global analyses of the Agreement and single-country studies, particularly of the U.S. and China. The global studies fall into three main modeling strands: (1) the first uses dynamic computable general equilibrium (CGE) models, often focusing on macroeconomic outcomes; (2) the second strand uses integrated assessment models (IAMs), which often include an environmental system in addition to economic and social components; and (3) the third strand uses partial-equilibrium or reduced-form energy models, which often provide more detail in energy sectors. Comparison studies help explain the implications of different modeling approaches and identify which results are robust and which are not.

For example, among global studies several common insights arise. First, the Agreement reduces global emissions relative to business as usual, but it does not put the world on track to stabilize concentrations or limit warming to $2{ }^{\circ} \mathrm{C}$. Second, across all of the studies the costs of complying with the pledges in the Agreement, either in terms of GDP or consumption, are small. Third, emissions trading can, in principle, significantly reduce global costs. Fourth, the impacts of the Agreement vary across countries: energy-exporting countries bear the greatest burden, followed by industrialized countries with relatively ambitious targets, and costs are lowest for developing countries with relatively loose targets.

Important differences across the studies also arise. Rogelj et al. (2016) examine eleven global studies reporting the implications of NDCs for global emissions by 2030 and find a wide range of baseline estimates of future emissions. Liu et al. (2017) survey recent modeling scenarios about China's carbon emissions in twelve global models and also find that baseline emissions vary significantly, with China's overall emissions growth between 2010 and 2030 varying between 21\% and $119 \%$. Partly due to these differences in baseline emissions, the models report very different $\mathrm{CO}_{2}$ taxes are needed to achieve the NDCs. For example, Babonneau et al. (2018) compare $\mathrm{CO}_{2}$ tax rates consistent with achieving the NDCs across seven models ${ }^{4}$ and find that in 2030, the

\footnotetext{
4 The models include GEMINI-E3, WITCH, DEN21+, GCAM, MERGE, GEM-E3, and EPPA.
} 
U.S. $\mathrm{CO}_{2}$ tax varies from $\$ 40$ to $\$ 109$ per ton of $\mathrm{CO}_{2}$, the tax for Europe varies from $\$ 45$ to $\$ 177$, and that for China varies from almost zero to $\$ 33$.

Differences such as these arise in other policy simulations. Stegman and McKibbin (2013) compare long-term projections across global models and show that even using similar methodology, projections can vary considerably, particularly for developing regions over longtime horizons. This highlights the importance of alternative model structures and assumptions in the differences in model projections. Rogelj et al. (2016) identify another four factors contributing to the differences: incomplete country and sector coverage, uncertain projections due to ambiguous targets (relative to business-as-usual scenarios), different approaches to accounting for land-use-related emissions, and estimation uncertainty of historical emissions and various metrics of translating $\mathrm{GHG}$ emissions into $\mathrm{CO}_{2}$-equivalence.

Among single-country papers, studies about China are the most numerous. Liu et al. (2017) show how long-term projections of China's economy and $\mathrm{CO} 2$ emissions differ across 11 global models and note that most project baseline emissions increasing through 2050. Mischke and Karlsson (2014) review 18 models developed by Chinese institutions and show that the growth of baseline emissions from 2010 to 2030 varies from $50 \%$ to $100 \%$. Baseline emissions heavily depend on baseline GDP projections. In these Chinese models, GDP growth varies from $200 \%$ to $350 \%$ by 2030 relative to 2010 across models, with average annual growth rates varying from $5.6 \%$ to $7.8 \%$ over the period. The models suggest a gradual long-term transition towards a lowcarbon economy in China, with no emissions peak or stabilization period before 2040 in the baseline. Some other studies also show strong emissions growth in baseline scenarios. McKibbin et al. (2015b) and Qi et al. (2016) both project that China's emissions will grow by about $120 \%$ from 2010 to 2030 . There are, however, a few studies at the other end. For example, Timilsina et al. (2018) project that emissions intensity falls by $58.7 \%$ by 2030 relative to the 2005 level in their baseline, and unsurprisingly their tax rates to achieve the NDC target are very small. All these studies also contain results of policy simulations but it is hard to compare them directly due to differences in the policy scenarios examined and the presentation of the results. For example, Qi et al. (2016) solve for a tax rate of $\$ 26$ per ton of $\mathrm{CO}_{2}$ emissions by 2030 to achieve China's carbon intensity targets. McKibbin et al. (2015b) first convert China's emissions intensity target into emissions levels and then solve for a tax rate. Instead of achieving emissions intensity targets, Liu et al. (2017) implement a given profile of $\mathrm{CO}_{2}$ taxes and then compare emissions paths across models.

There are also studies of U.S. climate policies. The Energy Modeling Forum (EMF) provides a series of comprehensive modeling exercises examining U.S. energy and climate policies. McFarland et al. (2018) and Barron et al. (2018) summarize results from 11 models in the EMF32 project on U.S. carbon tax scenarios. Although the EMF32 project did not focus on the Agreement per se it provides insights on the design and impact of carbon taxes in the U.S. For example, carbon prices cause significant reductions in $\mathrm{CO}_{2}$ emissions across all models, with the vast majority of the reductions occurring in the electricity sector. Economic costs, in terms of either GDP or welfare, are modest but vary across models, and these costs are offset by benefits from avoided climate damages and health benefits from reductions in air pollution. Emissions reductions do not significantly depend on the rebate or tax cut used to return revenues to the economy. Authors of the papers caution that model uncertainties are large beyond 2030. A few other studies are directly relevant to the U.S. NDC. Larsen et al. (2017) show that the U.S. emissions would fall by $15-19 \%$ by 2025 relative to 2005 under current policy, which is short of its $26-28 \%$ reduction commitment. Chen et al. (2018) assess the impacts of the U.S. withdrawal from the Agreement and argue that, without U.S. participation, increased reduction efforts required for the rest of the world to achieve the $2{ }^{\circ} \mathrm{C}$ goal result in significantly higher global cumulative mitigation costs from 2015 to 2100. Chen and Hafstead (2019) show that the carbon tax and economic cost of achieving the $28 \%$ reduction commitment by 2025 are modest, with a constant carbon tax of $\$ 43$ starting in 2019 and a real GDP loss of $0.45 \%$ in 2025 . They also show that delaying action increases the tax rate required to meet the target to $\$ 47$ if the policy is delayed to 2021 , and to $\$ 53$ if delayed to 2023 .

The studies summarized here use a wide variety of modeling approaches and focus on several global and national issues related to the Agreement. This paper fits into the strand of global studies that use dynamic CGE models. We make three contributions. First, we apply a global macroeconomic model that uniquely incorporates short-run rigidities, financial markets, transitional responses of central banks, and international capital flows driven by intertemporal savings and investment decisions. Importantly, a proportion of firms and households have forward-looking expectations, and this anticipation of NDC policies significantly affects short-run dynamic adjustments. Second, we consider the implications of unilateral withdrawal from the Agreement by the United States, China, and Australia. Third, we present a broader set of measures of the economic and environmental outcomes of the Agreement. Using this approach, we calculate the economic outcomes and welfare effects of the NDC policies, as other studies have done. However, we also estimate the monetized domestic co-benefits of reductions in fossil energy use and the global climate benefits (through 2030) contributed by each participating region in the model. Including monetized benefits allows us to calculate the net domestic benefits of the Agreement to each region.

Several caveats apply to our study, as they would to many others of this kind. The caveats primarily involve necessary simplifying assumptions. First, as noted above we only examine the impact of reducing $\mathrm{CO}_{2}$ from fossil energy use. To the extent that a country has significant baseline shifts in land-use emissions, non- $\mathrm{CO}_{2} \mathrm{GHGs}$, and the like, the stringency of the target we estimate could be higher or lower than would apply in practice. Likewise, countries may have abatement costs for other sources that are importantly higher or lower than those for energy-related $\mathrm{CO}_{2}$. Second, for simplicity, we assumed countries achieve their NDC targets with a stylized policy: $\mathrm{a} \mathrm{CO}_{2}$ price that applies to all fossil fuels with the revenue rebated to households in a lump-sum fashion. If countries adopt much less efficient policies or use carbon revenue differently, the macroeconomic outcomes could be different. For a modeling study of how revenue use matters, see the EMF32 project described in McFarland et al. (2018).

To construct a policy scenario, we must make assumptions about what actions are taken in the years other than those of the Agreement targets. For each region, we assumed that the corresponding government imposes a sequence of annual $\mathrm{CO}_{2}$ prices, starting in 2020 , that produces a linear decline in emissions levels from 2020 baseline levels to the NDC target in the target year. After the target year, we assumed $\mathrm{CO}_{2}$ prices stay at their target year levels.

A key element of the Agreement is the prospect of increasing the ambition of commitments every five years. The anticipation of these future more-stringent commitments could affect the emissions levels and economic outcomes we report here. Finally, in Article 6, the Agreement allows for the international transfer of "mitigation outcomes", suggesting the potential for some form of emissions trading that could lower overall costs. We assume each region achieves its target unilaterally. We do, however, compare our results to the implementation of the Agreement with a common carbon price across countries as an illustration.

\section{Modeling approach and baseline projections}

\subsection{The modeling approach}

The G-Cubed model is documented in McKibbin and Wilcoxen (1999, 2013). For this paper we extended the model by adding new country coverage for India and the Russian Federation, as well as a revised regional aggregation for Europe, which now includes both Western and Eastern European economies consistent with the Agreement 
groupings. The complete list of geographic regions in the model appears in Table 1.

The electricity sector in G-Cubed was also recently revised and now includes eight specific generation technologies: coal, natural gas, oil, nuclear, wind, solar, hydro and other (largely biomass and other renewables). A technical discussion of recent modeling improvements appears in McKibbin et al. (2015b). Table 4 contains the full list of sectors in the model.

Several features of G-Cubed are worth highlighting here. First, the model completely accounts for stocks and flows of physical and financial assets. For example, budget deficits accumulate into government debt, and current account deficits accumulate into foreign debt. The model imposes an intertemporal budget constraint on all households, firms, government, and countries. Thus a long run stock equilibrium obtains through the adjustment of asset prices, such as the interest rate for government fiscal positions or real exchange rates for the balance of payments. However, the adjustment towards the long-run equilibrium of each economy can be slow, occurring over much of a century.

Second, agents in G-Cubed must use money issued by central banks for all transactions. Central banks in the model set short term nominal interest rates to target macroeconomic outcomes (such as inflation, unemployment, exchange rates, etc.) based on Henderson-McKibbinTaylor monetary rules. These rules are designed to approximate actual monetary regimes in each country or region in the model. They tie down the long-run inflation rates in each country as well as allowing short term adjustment of policy to smooth fluctuations in the real economy.

Third, nominal wages are sticky and adjust over time based on country-specific labor contracting assumptions. Firms hire labor in each sector up to the point that the marginal product of labor equals the real wage defined in terms of the output price level of that sector. Any excess labor enters a pool of unemployed workers. Unemployment or, alternatively, excess demand for labor, causes the nominal wage to adjust to clear the labor market in the long run. In the short-run unemployment can arise due to structural supply shocks or changes in aggregate demand in the economy.

Fourth, rigidities prevent the economy from moving quickly from one equilibrium to another. These rigidities include nominal stickiness caused by: wage rigidities; lack of complete foresight in the formation of expectations; costs of adjustment in investment by firms with physical capital that is sector-specific in the short run; and the behavior of monetary and fiscal authorities who follow particular monetary and fiscal rules. Short term adjustment to policy changes like the Agreement

\section{Table 4}

Sectors in the G-Cubed model.

\begin{tabular}{lll}
\hline Number & Sector name & Notes \\
\hline 1 & Electricity delivery & Energy sectors other than generation \\
2 & Gas utilities & \\
3 & Petroleum refining & \\
4 & Coal mining & \\
5 & Crude oil extraction & \\
6 & Natural gas extraction & Goods and services \\
7 & Other mining & \\
8 & Agriculture and forestry & \\
9 & Durable goods & \\
10 & Nondurables & \\
11 & Transportation & \\
12 & Services & \\
13 & Coal generation & \\
14 & Natural gas generation & \\
15 & Petroleum generation & \\
16 & Nuclear generation & \\
17 & Wind generation & \\
18 & Solar generation & \\
19 & Hydroelectric generation & \\
20 & Other generation & \\
\hline
\end{tabular}

can be very different from the long-run equilibrium outcomes of the policy. The focus on short-run rigidities is important for assessing the impact of a major policy change over the initial decades of the policy's implementation.

Fifth, households and firms are represented as mixtures of two types of agents: one group which bases its decisions on forward-looking expectations and the other group which follows simpler rules of thumb which are optimal in the long run, but not necessarily in the short run. ${ }^{5}$ This heterogeneity in both households and firms distinguishes the model from other representative agent models.

\subsection{The baseline scenario}

We first solve the model from 2016 to 2100 to develop a baseline, or business as usual (BAU) scenario. This scenario assumes that regions continue policies they have already adopted and do not undertake new policies to achieve their NDCs. McKibbin et al. (2007) outline our approach to generating a baseline projection (which is complex in a model with rational expectations).

The key inputs to the baseline are the initial dynamics leading into 2016 (that is, the evolution of the economy from 2015 to 2016) and subsequent projections from 2016 forward for labor force growth and productivity growth by sector and by country. We take labor force growth from the United Nations Population Projections (2018). Our productivity projections follow the approach of Barro (1991) and as updated in Barro (2015). Over long periods, Barro estimates that the average rate at which individual countries catch up to the world-wide productivity frontier is $2 \%$ per year. We use the Groningen Growth and Development database (2018) to estimate the initial level of productivity in each sector of each region in the model. Given this initial productivity, we then take the ratio of this to the equivalent sector in the United States, which we assume is the frontier. Given this initial gap in sectoral productivity, we use the Barro model to generate long term projections of the productivity growth rate of each sector within each country. Where we expect that regions will catch up more quickly to the frontier due to economic reforms (e.g. China) or more slowly due to institutional rigidities (e.g. Russia), we vary the catchup rate over time. The calibration of the catchup rate attempts to replicate recent growth experiences of each country and region in the model. These sectoral productivity growth rates, together with the economy-wide growth in labor supply, are the exogenous drivers of sector growth for each country. The growth in the capital stock in each sector in each region is determined endogenously within the model.

In some cases we find that this procedure produces economic growth and energy-related $\mathrm{CO}_{2}$ emissions for some regions that deviate from the EIA's Annual Energy Outlook (EIA, 2018) and other national official forecasts. In those cases, to generate a BAU scenario that is closer to official projections, we adjust sectoral productivity to more closely approximate the $\mathrm{AEO}$ and other official projections.

Finally, in addition to assumptions about monetary policy rules, fiscal rules, and other institutional rigidities in the model, we assume no further adoption of climate policies in the baseline beyond those that existed in 2015 (prior to the Agreement).

Fig. 1 shows the model's BAU projections from 2015 to 2030 for global $\mathrm{CO}_{2}$ emissions from energy use across the major regions in the model. These projections do not include the NDC pledges that countries made as part of the Agreement. Importantly, they also do not include any impacts on the global economy of climate disruption, and neither do the modeling results for the policy scenarios. G-Cubed does not include the economic impact of climate damages, but later in the paper, we monetize the climate benefits from the policies we model using an estimate of the social benefit of reducing each ton of $\mathrm{CO}_{2}$.

\footnotetext{
${ }^{5}$ Appendix $\mathrm{C}$ examines the impact of alternative assumptions about the fraction of agents with foresight.
} 


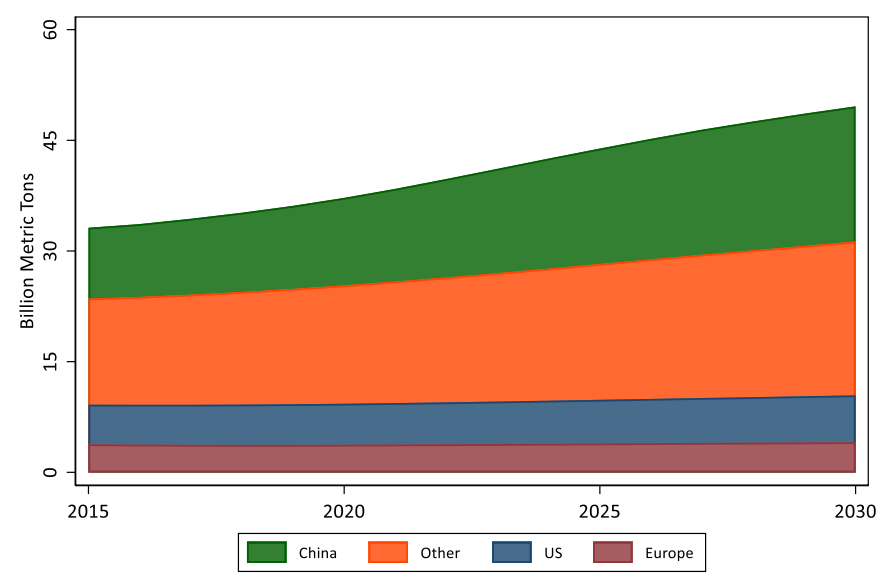

Fig. 1. Global $\mathrm{BAU} \mathrm{CO}_{2}$ emissions.

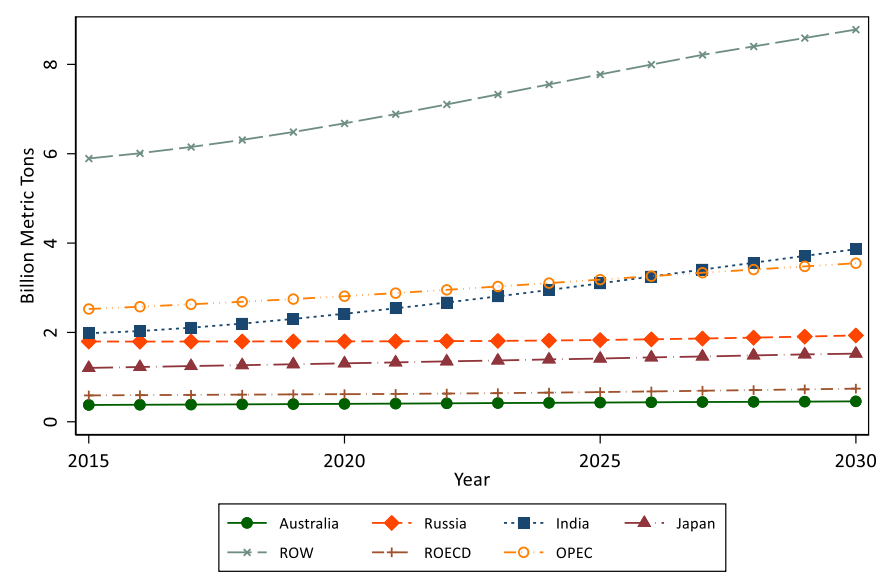

Fig. 2. $\mathrm{BAU} \mathrm{CO}_{2}$ emissions for other regions.

Fig. 2 presents the BAU projections for the regions in the model labeled as "Other" in Fig. 1, the wedge in orange. Fig. 2 illustrates the rising levels of emissions from emerging economies included in ROW and the increasing importance of India in global emissions.

Fig. 3 reports the emissions data from the previous figures as annual growth rates by region. The rates of growth in China and India, the two highest curves, stand out. While $\mathrm{CO}_{2}$ emissions per capita are low in these regions, their annual growth rates are high compared to the others.

These results suggest that without the implementation of the Paris $\mathrm{NDCs}$, growth in global $\mathrm{CO}_{2}$ emissions from energy use would be large and inconsistent with stabilizing atmospheric GHG concentrations. We also observe an increasingly large impact from emerging countries, particularly China and India.

Clearly, economic projections out to 2100 are highly uncertain. In particular, enormous uncertainty surrounds technological innovations that may occur in end-use energy efficiency, renewable electricity generation, electricity storage and transmission, biofuels, and fossil fuel supplies. Some innovations, particularly in renewable electricity generation, could lower BAU emissions and reduce the cost of reaching any given climate target. Our results thus rely to a significant extent on the assumptions used in constructing the BAU scenario. As indicated in Table 5, our baseline includes a significant amount of non-fossil energy penetration (including wind, solar, hydro, nuclear and other renewables) over the coming decades, especially in Australia, India and the United States. These results are driven by the interaction between assumptions we make regarding the rate at which costs decline and

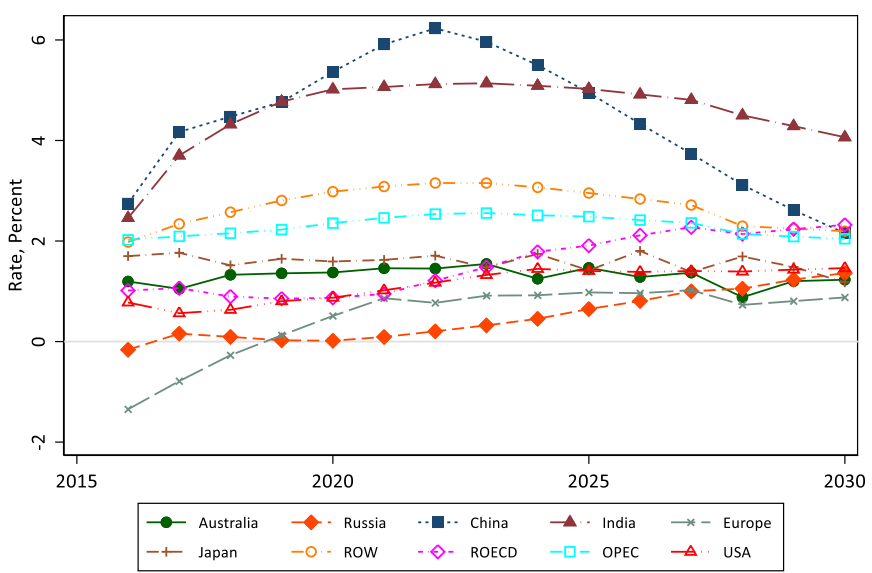

Fig. 3. Annual BAU emissions growth rate for each region.

Table 5

BAU renewable electricity by region, percent of total generation.

\begin{tabular}{lclc}
\hline Region & $\begin{array}{l}\text { Renewable } \\
\text { electricity in 2015 }\end{array}$ & $\begin{array}{l}\text { Renewable } \\
\text { electricity in 2030 }\end{array}$ & $\begin{array}{l}\text { BAU change in renewable } \\
\text { electricity 2015-2030 }\end{array}$ \\
\hline Australia & 9.8 & 30.4 & 20.6 \\
China & 12.8 & 18.1 & 5.3 \\
Europe & 44.8 & 48.9 & 4.1 \\
India & 12.6 & 23.1 & 10.5 \\
Japan & 24.5 & 25.8 & 1.3 \\
OPEC & 2.8 & 2.7 & -0.1 \\
ROECD & 67.8 & 65.3 & -2.5 \\
ROW & 21.4 & 21.6 & 0.2 \\
Russia & 5.3 & 5.5 & 0.2 \\
USA & 28.4 & 42.7 & 14.3 \\
\hline
\end{tabular}

endogenous price-driven responses by energy users in the model. If the costs of renewables fall faster than assumed, the Paris NDCs will be easier to achieve and the impacts of the Agreement (both economic and environmental) will be smaller than we report. On the other hand, if our projections for renewables are too optimistic and costs fall more slowly, impacts of the Agreement would be larger.

As discussed in Section 3, long-term projections of economic growth and $\mathrm{CO}_{2}$ emissions often differ significantly from one model to another. Mischke and Karlsson (2014) show that China's emissions growth from 2010 to 2030 varies from 50\% to 100\% in 18 Chinese models, and Liu et al. (2017) summarize that the emissions growth from 2010 to 2030 varies from $21 \%$ to $119 \%$. Our baseline emissions for China increase by $90 \%$ from 2015 to 2030 , and are thus at the high end of these projections.

\section{Outcomes of the Paris Agreement}

We assume that in 2016 - when the Agreement entered into force each region explicitly announces that starting in 2020 , it will impose a policy sufficient to achieve its Paris pledge. Each region reduces its emissions linearly from its baseline level in 2020 to its target level in the target year as shown in Table 3 by imposing a series of year-by-year prices on $\mathrm{CO}_{2}$ emissions. Revenue from the $\mathrm{CO}_{2}$ price is returned to households via lump-sum rebates. ${ }^{6}$ We solve for the requisite price path and examine the economic and emissions outcomes. This "Paris" scenario is our central set of results in the figures and tables below.

Although in practice countries may use any number of policies to reach their $\mathrm{NDC}$ goals, we apply $\mathrm{CO}_{2}$ prices with lump-sum recycling

\footnotetext{
${ }^{6}$ There is a large literature on the importance of revenue recycling. See McKibbin et al (2015a) for a summary and an analysis with the G-Cubed model.
} 
for three reasons. First, by imposing a common approach we can examine how differences in outcomes are determined by differences in the pledges and economies of the regions rather than on differences in policy design. Second, a price on $\mathrm{CO}_{2}$ is the most straightforward of a wide range of carbon pricing policies, including taxes, emissions trading, or hybrid policies. There is broad agreement in the economics literature that carbon pricing would have the lowest economic costs among policies that would achieve any given emissions target. Third, solving for an emissions price provides a direct and transparent way to measure the marginal cost of each region's target.

In addition to examining the full Agreement, we explore the implications of unilateral withdrawal by three regions: the United States, China, and Australia. Considering withdrawal by individual countries illustrates interesting aspects of different regions in implementing the Agreement. We choose the United States in light of its announced withdrawal from the Agreement by 2020; China because of its role as the world's largest emitter, and because it has a high BAU path of emissions; and Australia because fossil fuels are one of its major source of income through exports. In all three cases, we assume that the regions remaining in the Agreement adjust their policies as needed to continue to hit their Paris targets.

Importantly, the non-participation cases only illustrate the economic and emissions impact of participating or not in the Agreement, all other things equal. They are not in any sense policy proposals or predictions. Moreover, they do not include international political consequences or any economic retaliation against countries that withdraw, so in that sense they are likely to be overly optimistic about the benefits to non-participants of withdrawing.

Finally, we discuss the sensitivity of the model's results to key parameter values in Appendix C. In particular, we examine the impact of alternative assumptions about the degree to which consumers and firms have forward-looking expectations. We find that changes in these assumptions largely cause parallel changes in the model's baseline and Paris Agreement trajectories: they have relatively small effects on the policy impacts of the Agreement relative to the baseline.

\subsection{Full participation}

Fig. 4 shows the path of global $\mathrm{CO}_{2}$ emissions from energy use under five scenarios: BAU, Paris, and the three scenarios with a single nonparticipant ("US out," “AUS out," and "CHI Out”). The Agreement significantly reduces emissions relative to BAU; emissions are lower than baseline by 13 billion tons by 2030 . However, emissions do not decline in absolute terms, let alone follow a path consistent with a $2{ }^{\circ} \mathrm{C}$ stabilization scenario.

Fig. 4 also shows that among the three opt-out scenarios, the biggest increase in emissions would result from the departure of China. Almost

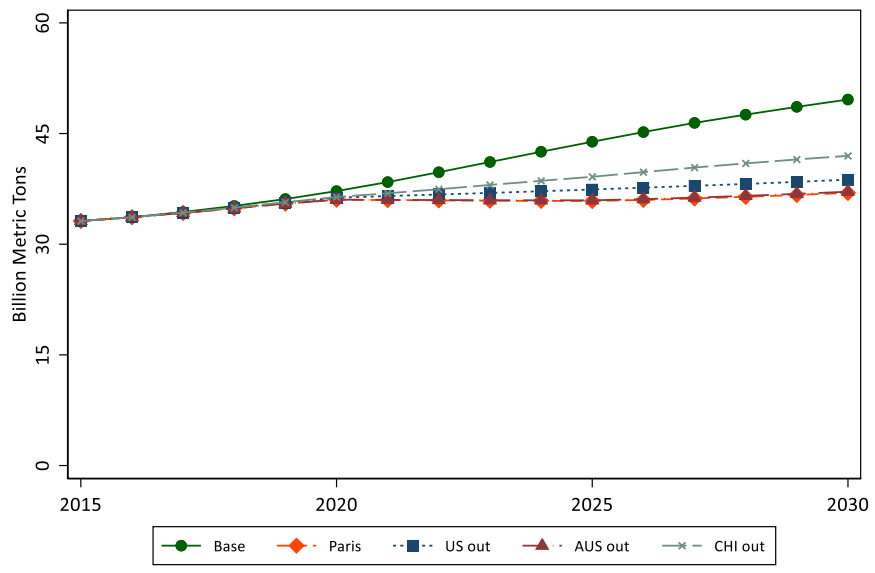

Fig. 4. Global $\mathrm{CO}_{2}$ emissions levels under Paris and other scenarios. half of the reduction in global emissions comes from China's participation, so China's withdrawal would dramatically reduce the effectiveness of the Agreement. Section 5.2 discusses the further implications of the opt-out scenarios.

Fig. 5 shows the change in the growth rate of emissions in each region under the Agreement. Emissions begin to change in 2016 in anticipation of the $\mathrm{CO}_{2}$ prices that will take effect beginning in 2020. We assume the $\mathrm{CO}_{2}$ prices remain constant after the target year, which is 2025 for the United States and 2030 for all other regions. Once carbon prices stabilize, economic growth causes each country's emissions growth to revert gradually to its baseline rate, although the level of emissions remains permanently below BAU. Two regions with unusual trajectories are the United States, which has an earlier target year than the others, and China, whose existing policies under BAU begin sharply reducing the growth of emissions after 2020 even without additional policies to hit its NDC target.

The reduction in the growth rate in emissions ranges from a low of $1 \%$ for OPEC to nearly $6 \%$ for Japan. The absolute reduction in emissions differs enormously across regions because of the scale of each country's emissions, as shown in Fig. 6. The biggest reduction in emissions is from China, followed by the United States.

Fig. 7 shows the percentage change in emissions under the Agreement relative to the BAU scenario. Note that this is not the change relative to a historical year's emissions (which is the formulation of many NDCs) but rather the percentage change relative to what emissions would have been without the emissions control policy. The anticipation of the prices starting in 2020 causes declines in fossil fuel $\mathrm{CO}_{2}$ between

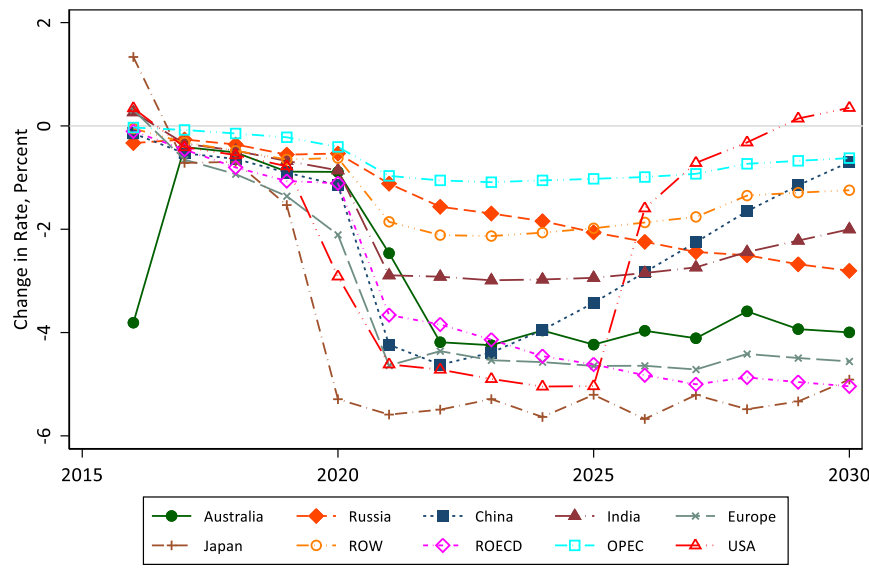

Fig. 5. Change in $\mathrm{CO}_{2}$ emissions growth rate under Paris relative to BAU.

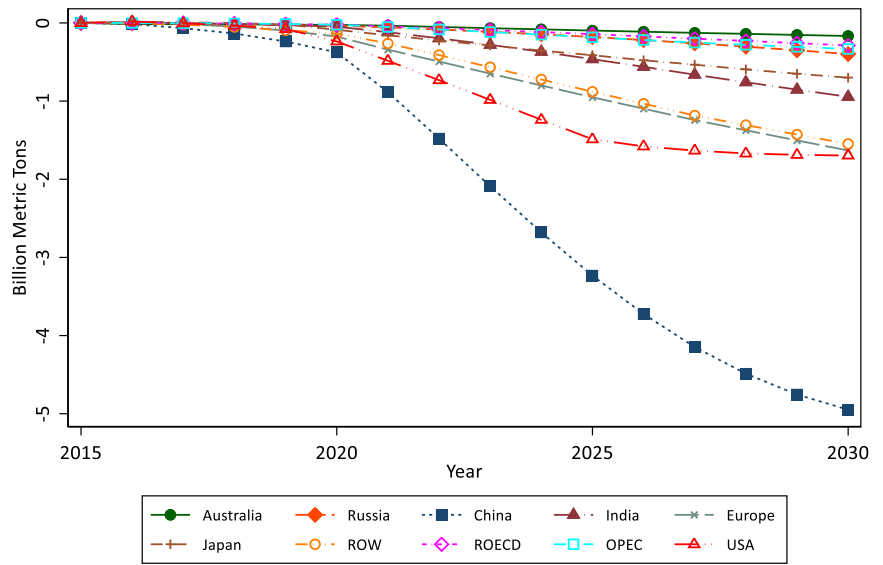

Fig. 6. Change in $\mathrm{CO}_{2}$ emissions under Paris relative to BAU. 


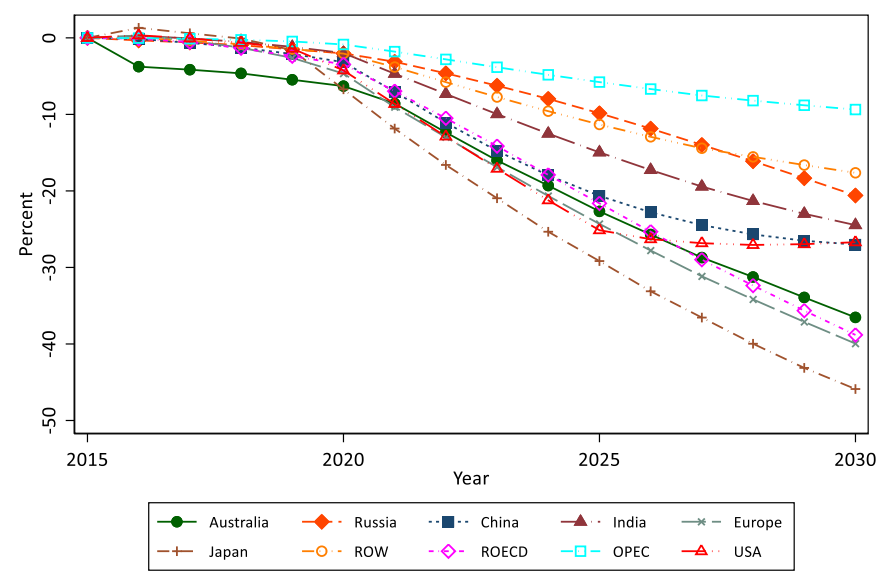

Fig. 7. Percent change in $\mathrm{CO}_{2}$ emissions under Paris relative to BAU.

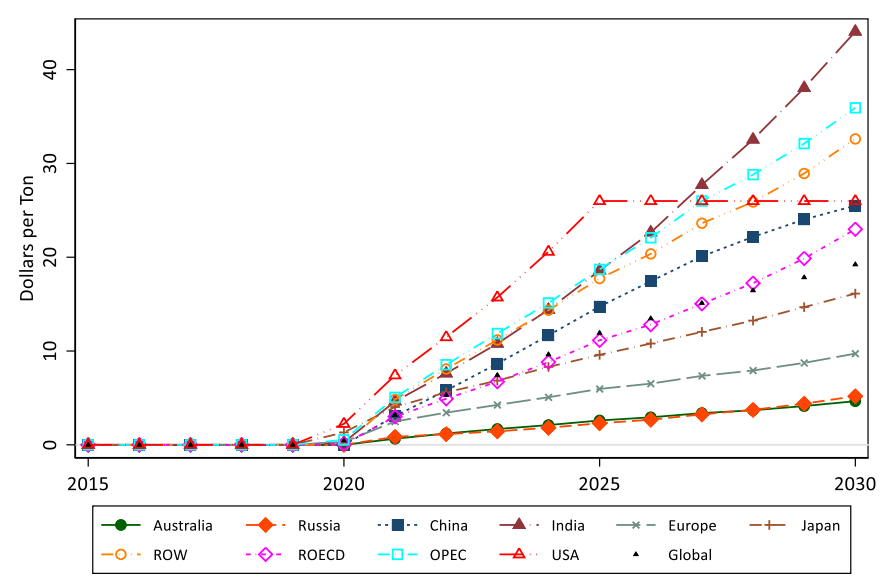

Fig. 8. $\mathrm{CO}_{2}$ prices under Paris.

2016 and 2020, particularly in Australia. By 2030, emissions reductions mirror the target-to-baseline figures in column seven of Table 3. For example, OPEC emissions fall by about $10 \%$ relative to BAU, and Japanese emissions fall by almost half. U.S. emissions are down by about $25 \%$ by its target year of 2025 and remain constant after that.

Fig. 8 shows the $\mathrm{CO}_{2}$ price trajectory for each region. For reference, we also include a uniform global $\mathrm{CO}_{2}$ price (shown as a sequence of small triangles) that would achieve the same overall reduction relative to the global BAU emissions as the Agreement. We express all prices and values in this paper in constant 2015 dollars. Owing to the anticipation of the policy change, by 2020 emissions in almost all regions are already below $\mathrm{BAU}$, and therefore their initial $\mathrm{CO}_{2}$ prices in 2020 are zero. The initial price is not zero for the United States, however, because financial capital flows into the United States at rates above BAU between 2016 and 2020 as returns on investment in the United States go up relative to other regions. The U.S. price is, therefore, positive in 2020: \$US 2. In all regions, the price increases over time until the target year, at which point it levels off by design. By $2030, \mathrm{CO}_{2}$ prices vary by significantly across regions, from \$US 5 in Russia and Australia to \$US 44 in India. With only five years of policy implementation before its 2025 target year, the U.S. price is higher than in other regions, leveling off at \$US 26 per ton of $\mathrm{CO}_{2}$.

Fig. 9 compares the regions by plotting the $\mathrm{CO}_{2}$ price from Fig. 8 against the percentage reduction in emissions from Fig. 7. The curves are trajectories over time and not, strictly speaking, marginal abatement cost curves. However, they are a convenient way to characterize the relative difficulty of driving down $\mathrm{CO}_{2}$ emissions in different

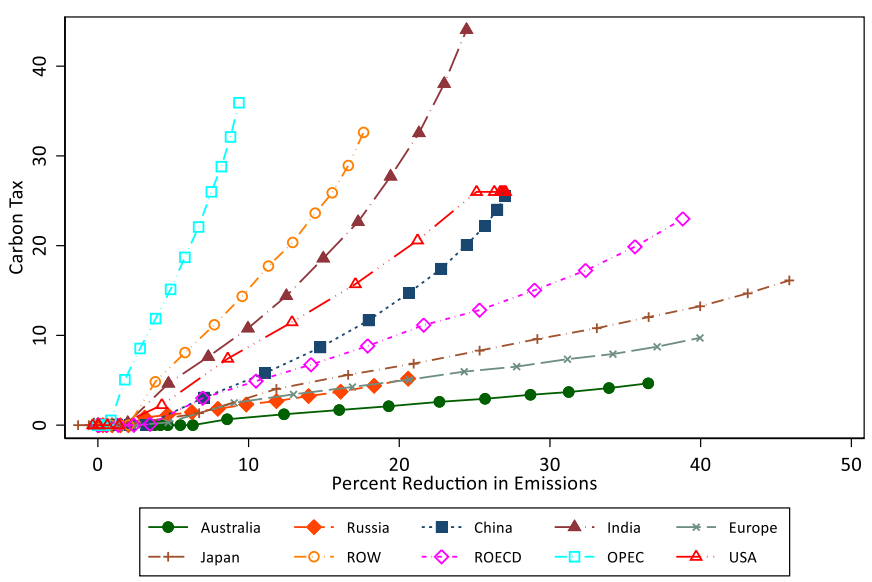

Fig. 9. $\mathrm{CO}_{2}$ price vs. percent reduction in emissions.

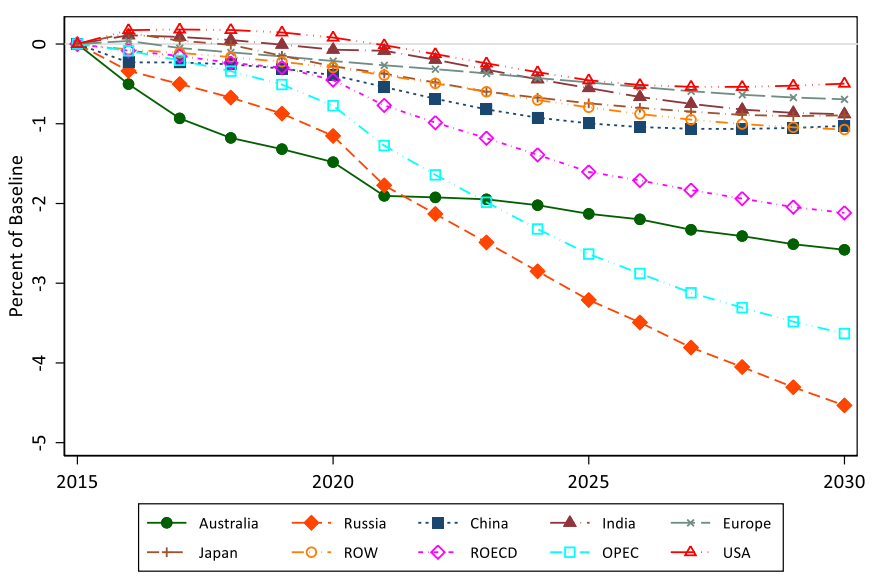

Fig. 10. Change in real GDP under Paris relative to BAU.

regions. Several results are of interest. First, the three regions where percentage reductions in emissions are the most difficult-in the sense that they require the largest $\mathrm{CO}_{2}$ prices-are OPEC, ROW (developing countries not included elsewhere), and India. Second, $\mathrm{CO}_{2}$ prices in China and the US are in the middle of the pack in both prices and percentage reductions in emissions and are similar to one another. Third, the regions where percentage reductions are easiestin the sense of requiring the lowest prices-are Australia, Europe, Russia, and Japan. Fourth, among emerging economies, China's percentage emissions reduction is about the same as that of India but its $\mathrm{CO}_{2}$ price is only about half as large.

These sharp variations between regions are driven by several factors, including the carbon intensity of each fossil fuel, the values of different fuels in each region's energy mix, baseline price levels, the relative shares of different fossil fuels in electricity generation, and the sectoral patterns of production and consumption.

Fig. 10 shows the change in GDP relative to BAU for all regions. Recall that in G-Cubed, neither the baseline nor the policy scenario accounts for the economic effects of climatic disruption. Owing to the anticipation of the policy, GDP falls for some regions beginning in 2016 even though the actual $\mathrm{CO}_{2}$ prices do not take effect until 2020. GDP is below BAU for all regions between 2020 and 2030, and it falls most for OPEC and Russia, which rely heavily on fossil fuels as both a domestic energy source and as an export. In the period before 2020, Australia experiences relatively large GDP declines owing to anticipation of its policies and those of the rest of the world. However, over time, the increased penetration of renewables and lower use of fossil fuels along 


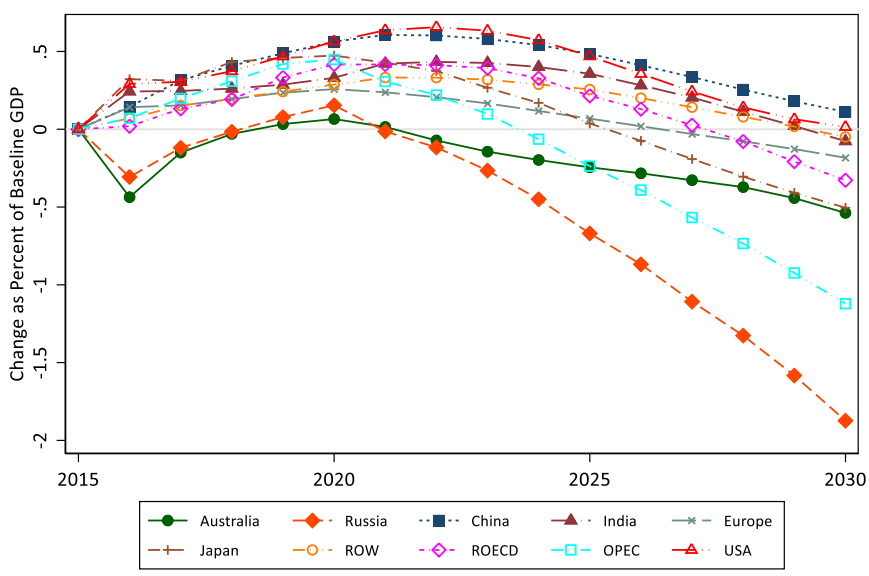

Fig. 11. Change in private consumption under Paris relative to BAU.

Australia's baseline path reduce its losses relative to other regions (see Fig. 3, where Australia's emissions growth is among the lowest of the regions during the years between about 2024 and 2030). The United States experiences a decline of about one half of 1\% of GDP in its target year of 2025 relative to its baseline real GDP growth from 2015 to 2025 of over $20 \%$.

The impact on consumption is important to welfare results; thus in Fig. 11, we show the change in private consumption relative to BAU. Initially, consumption rises (except in Russia and Australia) and then gradually falls. Three main factors drive this. First, revenue from the $\mathrm{CO}_{2}$ price goes back to households via lump-sum rebates. In the model, only $30 \%$ of consumers are forward-looking (i.e., $70 \%$ are liquidity constrained), and therefore the additional household income from rebates raises consumption for several years (until the $\mathrm{CO}_{2}$ price is high enough to slow the economy significantly). While this appears like a double dividend (lower emissions with higher consumption), it is a result that disappears by $2030 .{ }^{7}$ Second, the $\mathrm{CO}_{2}$ price reduces investment because the after-tax return on capital in fossil fuel sectors falls. Even though investment in renewables rises, the investment decrease in fossil fuel sectors and fossil-fuelintensive activities dominates that in the short run, so total investment falls. As investment declines, firms reduce retained earnings and hence provide relatively larger dividends to households, which helps to boost consumption further. Third, the fall in real interest rates causes forward-looking households to discount their future income at a lower rate, which tends to raise wealth, and thus consumption, in the near term.

The welfare effects of the Paris scenario appear in Fig. 12. We measure the effects by computing an intertemporal equivalent variation (EV) for each region: that is, the change in wealth, at baseline prices, that is equivalent to the policy's impact on households' intertemporal utility in each region. To put the EVs in context, we report each as a percent of baseline wealth. Fig. 12 shows that participating in the Agreement creates positive economic welfare benefits for China, India, Japan, ROW, and the United States, but negative economic welfare effects for Australia, OPEC, the rest of the OECD, and Russia. Europe is largely unaffected. The figure shows that the economic welfare effects range from -1.7 to $+0.8 \%$ of baseline wealth.

As with the other economic outcomes shown so far, the EVs in Fig. 12 do not account for the benefits of reduced climatic disruption or local environmental and other benefits that result from the decline in fossil

\footnotetext{
7 We undertook a great deal of sensitivity analysis including the share of forward- and backward-looking consumers but this result was not sensitive to this assumption. We also undertook sensitivity analysis on the revenue recycling assumptions for the Energy Modeling Forum 32 published in McKibbin et al. (2018).
}

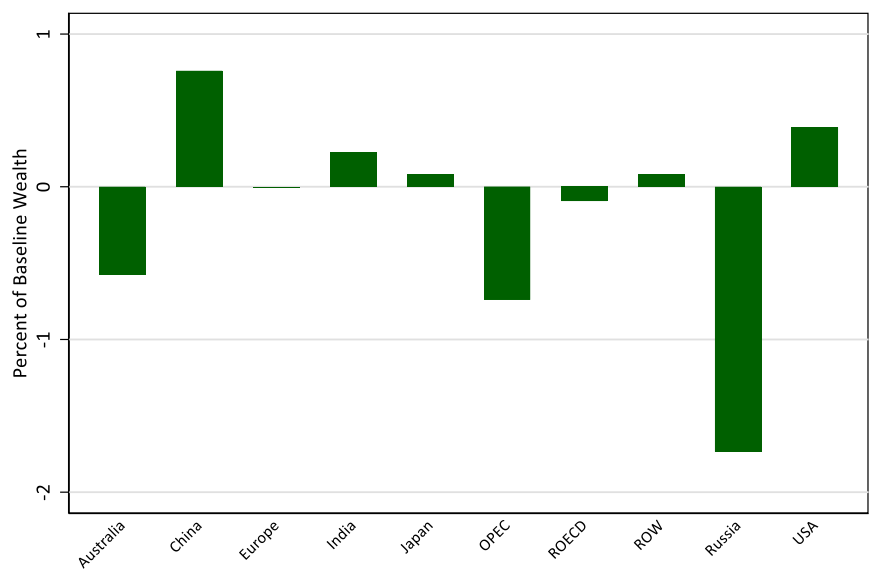

Fig. 12. Equivalent variations as a percent of baseline wealth under the Paris simulation.

fuel combustion. These domestic ancillary effects, also known as cobenefits, vary by fuel and location. For coal and natural gas, cobenefits are primarily reductions in mortality risks from air pollution. For gasoline and road diesel, co-benefits also include reduced road congestion, traffic accident risk, and road damage. Other policies may more efficiently achieve these benefits, but to the extent that they arise from the $\mathrm{CO}_{2}$ prices, they are relevant constituents of the overall net effects of pricing $\mathrm{CO}_{2}$ emissions.

Parry et al. (2015) enumerate the domestic non-climate external costs associated with fossil fuels in countries around the world. The authors estimate a price on $\mathrm{CO}_{2}$ that would be in countries' own interest, i.e., the price that would internalize those external costs. The authors apply estimates of country-level non-climate damages by fossil fuel product, using simple rules of thumb for the responsiveness of fuel use to $\mathrm{CO}_{2}$ pricing. ${ }^{8}$ Their estimates primarily reflect: (1) health cobenefits from reduced air pollution, especially those associated with fine particulate matter from stationary sources such as coal plants; and (2) benefits from reductions in automobile externalities including air pollution, traffic congestion, accidents and road damage. ${ }^{9}$ The estimates vary across countries in part due to variations in the populations that benefit from the improvements and in part due to pre-existing fuel taxes and subsidies. For example, estimated co-benefits from $\mathrm{CO}_{2}$ pricing in China are high because almost all of its $\mathrm{CO}_{2}$ reductions come from reductions in coal use. That reduces fine particulates substantially, and the population that benefits from the reduction is large. Table 6 reports the per-ton domestic co-benefit values we apply below, which in some cases are rough aggregations of the Parry et al. (2015) values to match the regions in the model.

We apply the per-ton dollar values in Table 6 to the reductions in $\mathrm{CO}_{2}$ emissions in each year through 2030 to approximate the streams of co-benefits in each region or country. ${ }^{10}$ We then take the present value of each region's stream to obtain co-benefit measures that we can add to the EVs in Fig. 12. Fig. 13 shows each of the following in billions of 2015 U.S. dollars: the EVs of the NDC policies; the present values of the domestic co-benefits; and the sum of the two (in blue). The figure shows that for most regions, the welfare effects of the emissions control policy are small (positive or negative) relative to the domestic co-

\footnotetext{
${ }^{8}$ See Parry et al. (2014) for details of estimates of external costs by country, fuel, and type of damage.

9 There is an emerging literature on co-benefit estimation such as Creutzig and He (2009), Mayrhofer and Gupta (2016), Markandya et al. (2018), Ortolano (2018), Vandyck et al. (2018) and Xie et al. (2018). The estimates can significantly vary across studies due to different benefit scope, sector coverage, estimation approaches, etc.

10 As noted earlier, this calculation is a first-order approximation that does not account for interactions between changes in environmental conditions and decisions about production and consumption. Moreover, it is driven entirely by non-climate externalities, so it is a lower bound on the overall benefits from reducing emissions.
} 
Table 6

Values of domestic co-benefits from reduced fossil fuel use. ${ }^{\text {a }}$

\begin{tabular}{lll}
\hline Region & $\begin{array}{l}\text { Co-benefits, \$ per metric } \\
\text { ton of } \mathrm{CO}_{2} \text { abated }\end{array}$ & Notes \\
\hline Australia & $\$ 11.50$ & $\begin{array}{l}\text { Australia } \\
\text { China }\end{array}$ \\
Europe & $\$ 63$ & Rough average of European countries \\
India & $\$ 52$ & India \\
Japan & $\$ 35$ & Japan \\
OPEC & $\$ 57.50$ & Average for large emitters \\
ROECD & $\$ 25$ & Based on Canada \\
ROW & $\$ 30$ & Rough average of developing countries \\
Russia & $\$ 85$ & Russia \\
USA & $\$ 36$ & United States \\
\hline
\end{tabular}

a After Parry et al. (2015), Fig. 7.

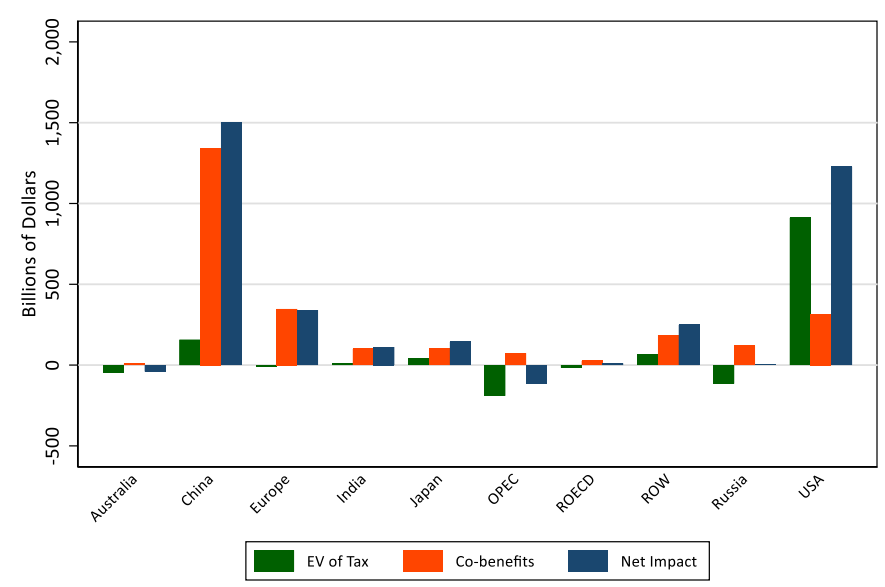

Fig. 13. Economic and ancillary domestic welfare effects under Paris relative to BAU through 2030.

benefits. All regions except Australia and OPEC experience positive net benefits from participating in the Agreement.

The domestic co-benefits shown in Fig. 13 do not include the value of decreased climate change. Climate change benefits are captured in Fig. 14, which shows the global benefits produced by each region's reduction in $\mathrm{CO}_{2}$ emissions using an illustrative social cost of carbon equal to \$US 42 . To be clear, these are global benefits, not the benefits to individual regions: the value for the United States, for example, indicates that its emissions reductions contribute about $\$ 370$ billion in benefits to the global community. The benefits produced by China's

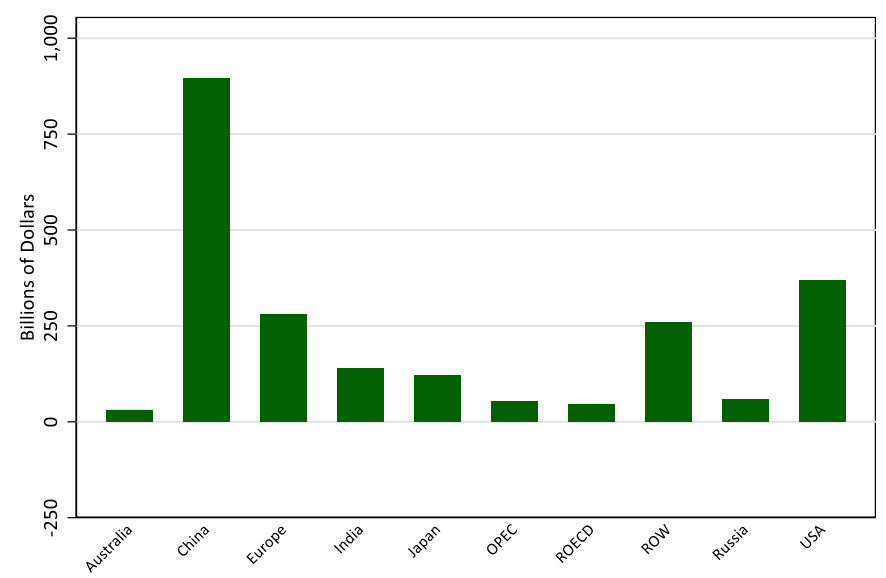

Fig. 14. Global $\mathrm{CO}_{2}$ benefits generated by each region under Paris.
Table 7

Alternative measures of stringency of the NDCs.

\begin{tabular}{lcllcc}
\hline Region & $\begin{array}{l}\mathrm{CO}_{2} \text { price } \\
\text { in 2030, } \\
\text { \$US }\end{array}$ & $\begin{array}{l}\text { Change } \\
\text { in 2030 } \\
\text { emissions, \% }\end{array}$ & $\begin{array}{l}\text { Change } \\
\text { in 2030 } \\
\text { GDP, \% }\end{array}$ & $\begin{array}{l}\text { EV, \% of } \\
\text { baseline } \\
\text { wealth }\end{array}$ & $\begin{array}{l}\text { Net impact, \% } \\
\text { of baseline } \\
\text { wealth }\end{array}$ \\
\hline Australia & 5 & -37 & -2.6 & -0.6 & $-\mathbf{0 . 5}$ \\
China & 26 & -27 & -1.0 & 0.8 & 7.3 \\
Europe & 10 & -40 & -0.7 & 0.0 & 0.2 \\
India & $\mathbf{4 4}$ & -25 & -0.9 & 0.2 & 2.2 \\
Japan & 17 & $-\mathbf{4 6}$ & -0.9 & 0.1 & 0.3 \\
OPEC & 36 & -9 & -3.6 & -0.7 & $-\mathbf{0 . 5}$ \\
ROECD & 23 & -39 & -2.1 & -0.1 & 0.1 \\
ROW & 33 & -18 & -1.1 & 0.1 & 0.3 \\
Russia & 5 & -21 & $-\mathbf{4 . 5}$ & $-\mathbf{1 . 7}$ & 0.1 \\
USA & 26 & -27 & -0.4 & 0.4 & 0.5 \\
\hline
\end{tabular}

participation are the largest of all at $\$ 896$ billion and account for about $40 \%$ of the total.

Table 7 presents several measures of the economic impact of the NDCs across regions: the price in 2030, which reflects the marginal cost of the NDC; the percent reduction in emissions relative to BAU, which shows the proportional contribution to the overall goal of reducing emissions; the percent reduction in GDP relative to BAU, which is a rough measure of the average cost of the policy; the equivalent variation as a percent of baseline wealth, which indicates the welfare impact of the $\mathrm{CO}_{2}$ price alone; and the net impact, including domestic cobenefits, also expressed as a percent of baseline wealth. Bold figures indicate the most ambitious (or least favorable) row in each column.

The relative ranking of regions from most to least stringent varies considerably with the measure used and is not at all apparent from the NDCs in Table 2. India's $\mathrm{CO}_{2}$ price in 2030 , for example, is the highest by far, but its reduction in GDP is towards the middle of the group. After accounting for domestic co-benefits, India has one of the best overall outcomes. In contrast, Russia experiences the largest reduction in GDP and has the worst EV outcome, but is still better off overall after accounting for co-benefits. The country gaining the most from the Agreement is China, which has a positive EV and, after accounting for domestic co-benefits, has the largest overall net gain by far. The only regions that experience an overall loss are Australia and OPEC, where cobenefits are relatively small and do not offset the negative EV associated with the Agreement.

Our net impact results are encouraging but it is important to note two caveats. First, the country-level co-benefit rates per unit of carbon abated are imprecisely known and could be lower than the values used here. As mentioned above, estimates vary significantly across

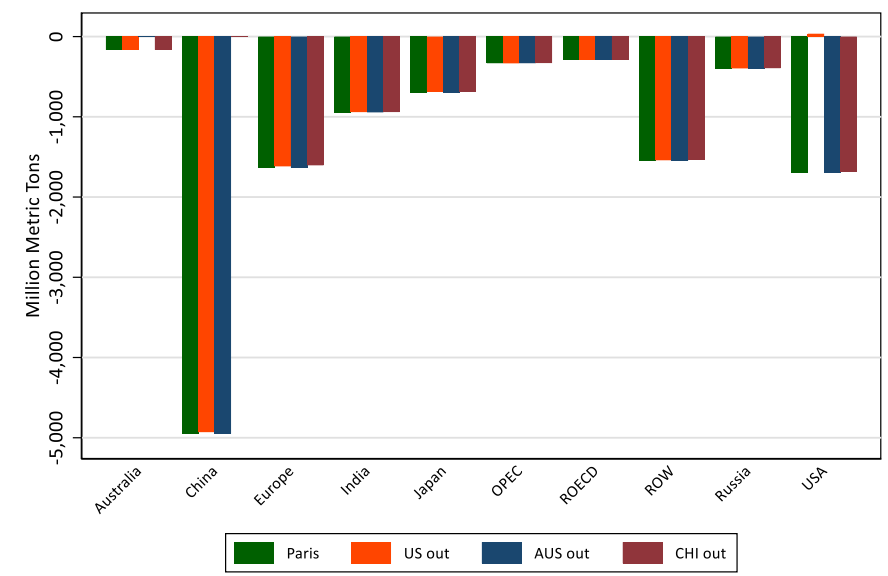

Fig. 15. Change in $\mathrm{CO}_{2}$ emissions under Paris and withdrawal scenarios in 2030 relative to BAU. 


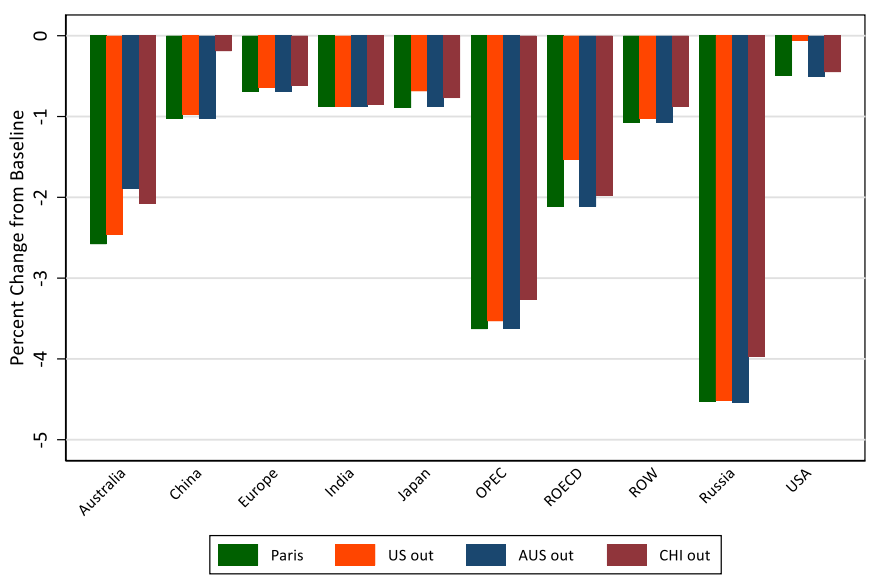

Fig. 16. Change in real 2030 GDP relative to BAU under policy scenarios.

studies. Moreover, co-benefits per unit of carbon may decrease as abatement increases and the environment becomes cleaner.

The second caveat is that the marginal costs of emissions reductions are likely to be convex: larger as the policy becomes more stringent. If so, welfare costs would be expected to rise faster than linearly as abatement increases. Co-benefits, in contrast, would increase linearly at best. In our simulations, the abatement levels and tax rates for the Agreement are relatively small, resulting in a tax rate around $\$ 30$ or less by 2030 for most regions, and domestic co-benefits exceed the welfare costs for most regions. However, more ambitious policies beyond 2030 could cause welfare costs to increase more rapidly than co-benefits. If so, our positive net impact results would no longer hold.

In addition, the presence of substantial ancillary benefits, even from modest carbon prices, raises an important question: Why have countries not already adopted policies to reduce those external costs? Some of the costs, such as conventional air pollution and traffic congestion, can be abated cost-effectively by other policies, and Table 6 suggests some countries are leaving large non-climate benefits on the table. Nonetheless, to the extent that countries commit to particular climate goals, a complete accounting of the ensuing benefits and costs is warranted.

\subsection{The impacts of withdrawals by individual countries}

This section explores the impacts of selected regions withdrawing from the Agreement. As described above, the regions that are the focus of this section are China, the United States, and Australia. Each region is assumed to withdraw unilaterally, with all other regions achieving their NDC targets.

Fig. 4 indicates the effect of each region's withdrawal on global emissions of $\mathrm{CO}_{2}$. China has a major impact; its withdrawal reduces the impact of the Agreement by about half. The United States also has a large impact, but it far smaller than that of China. Australia's domestic emissions, in contrast, are small relative to China and the United States. Since its exports of fossil fuels are subject to a carbon price whether or not Australia itself participates in the Agreement, Australia's withdrawal has little impact on global emissions.

Fig. 15 shows the emissions outcomes from each region under the four different policy scenarios. Note that by assumption, regions that stay in the Agreement continue to meet their NDCs even when one region withdraws.

Fig. 16 shows GDP impacts in 2030 by region under the Agreement and the three withdrawal scenarios. For all three countries, withdrawing from the Agreement still results in lower GDP than the baseline. For China and the United States, the resulting change is small: nonparticipation comes close to eliminating the GDP impact. For Australia, however, the Agreement still has a significant impact on GDP, even when Australia does not participate. These losses occur because Australia's exports of fossil fuels are still subject to the $\mathrm{CO}_{2}$ price in other regions, and the revenue is collected outside Australia.

Importantly, the values in Fig. 16 are changes in the level of GDP relative to BAU more than a decade in the future (2030), and they are generally small: about a typical year's GDP growth or less. To put these values in perspective for our selected countries, Fig. 17 shows their real GDP levels relative to 2015 under the BAU (Base), Paris, and
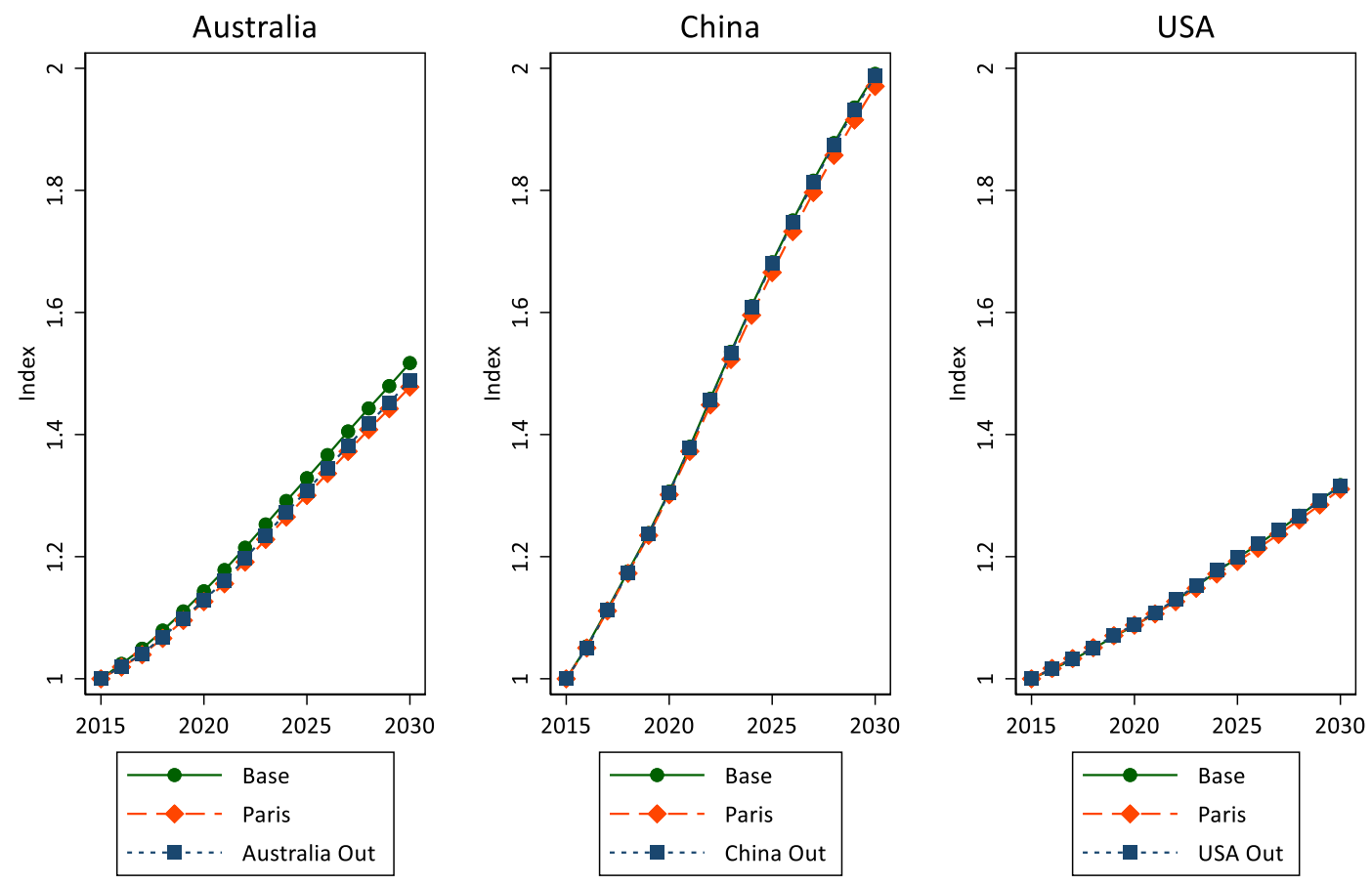

Fig. 17. Real GDP relative to 2015 values for selected regions. 


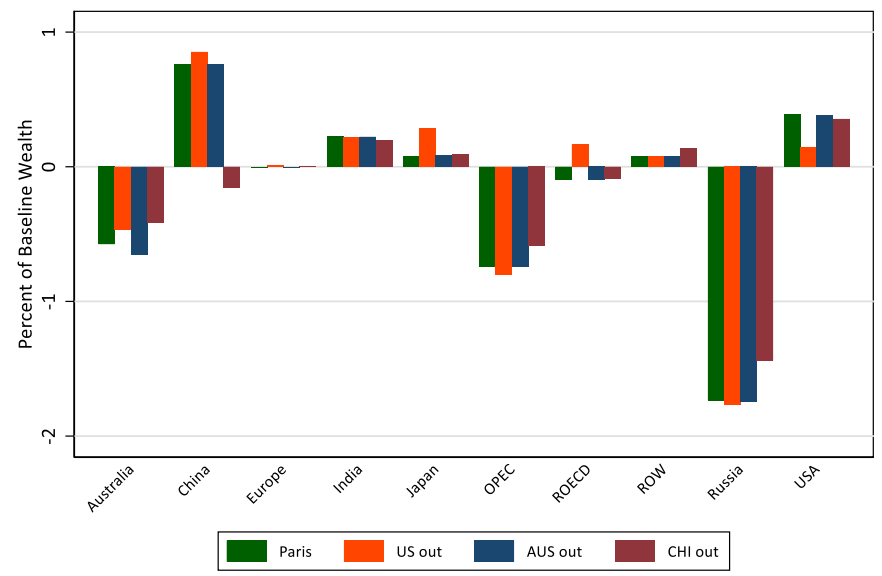

Fig. 18. Equivalent variations relative to wealth under policy scenarios.

withdrawal scenarios. The figure makes clear that the economic impacts of the Agreement are small compared to the underlying growth in GDP in all three economies. There is little to be gained in terms of GDP for each region by withdrawing from the Agreement. More importantly, we show below that a more complete accounting framework that includes environmental co-benefits indicates that participating in the Agreement is in the self-interest of almost all regions-that is, that countries withdrawing from it make themselves worse off.

Fig. 18 shows the equivalent variations by region through 2030 under the Agreement and the alternative withdrawal scenarios. The results for the Agreement scenario reframe the results shown in Fig. 13 from billions of dollars to the percent of baseline wealth. Fig. 18 allows a comparison of the relative welfare effects of the policy scenarios, not counting the domestic co-benefits shown in Fig. 13 or global climate benefits. Even abstracting from those important benefits, all three countries are better off participating in the Agreement than withdrawing. The welfare effects of the NDC policies are small for most regions: increases or decreases of less than one half of $1 \%$ of baseline wealth.

Fig. 19 adds the present value (through 2030) of the domestic cobenefits of achieving the NDCs to the EV values in Fig. 18. Once we add in the domestic co-benefits, nearly all of the policy outcomes are positive, with the exception of Australia and OPEC. Note the difference in the scales of the vertical axes of Figs. 18 and 19. Accounting for domestic co-benefits increases the estimated benefits of achieving the NDCs for some regions by one to two orders of magnitude, particularly for China, India, and Russia. Also, this addition does not change the

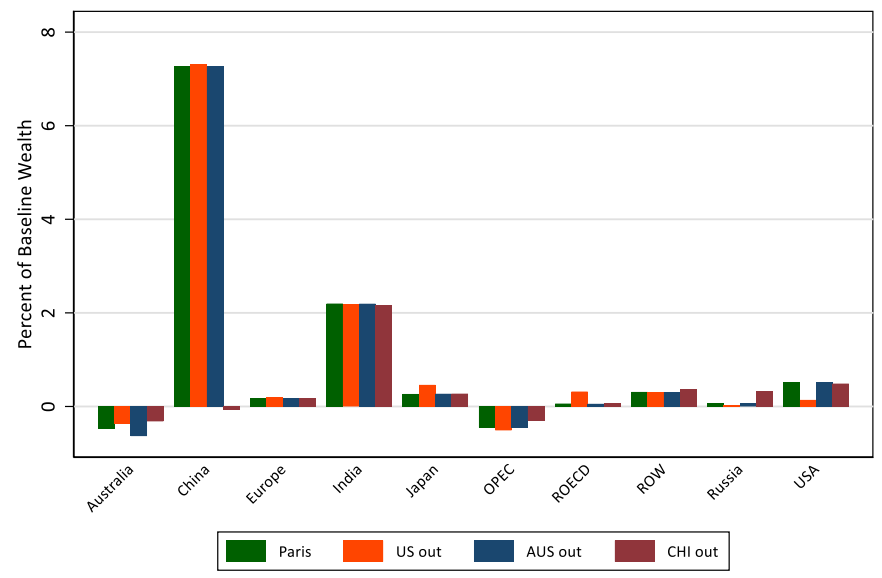

Fig. 19. EVs and domestic co-benefits relative to wealth under policy scenarios.

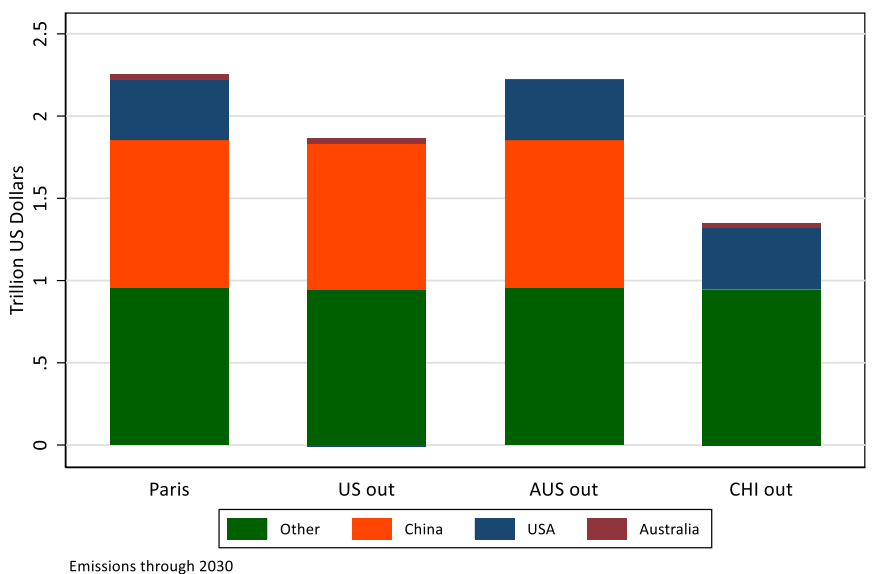

Fig. 20. Total PV of $\mathrm{CO}_{2}$ benefits through 2030 by policy scenario.

result that none of the three regions is better off if it unilaterally withdraws.

Fig. 20 shows the present value of $\mathrm{CO}_{2}$ benefits for the world under each policy scenario. The figure adds the benefits of emissions abatement through 2030 relative to the no-policy baseline. Under the Agreement, the present value of environmental benefits globally is around \$US 2.25 trillion. The largest environmental gains come from the participation of China and the rest of the world (the green bars labeled "Other"). The unilateral withdrawal of the United States has a higher environmental cost to the world than the economic gains to the United States of withdrawing. More importantly, the gain in GDP for the United States from withdrawal is smaller than the environmental benefits foregone by withdrawing.

\section{Conclusion}

This study explores the global economic and environmental implications of the NDCs that form the basis of the Agreement on climate change. Although the NDCs as a group fail to stabilize global emissions, they do have significant implications for the emissions and economic outcomes of the individual regions. In particular, we find that the differential targets across regions correspond to very different levels of impact, whether measured by the $\mathrm{CO}_{2}$ price required or the effects on GDP and welfare that result.

Perhaps more importantly, we observe that co-benefits from reductions in conventional pollutants are sufficiently large that even without accounting for reductions in climate change, every region receives a net benefit from participating in the Agreement. We also show that the globe's two largest $\mathrm{CO}_{2}$ emitters, China and the United States, are both better off participating in the Agreement than withdrawing from it even before accounting for co-benefits: in both countries, the equivalent variation of participating is larger than that of withdrawing. Finally, we end by observing that the climate benefits produced by the Agreement are large, even though the NDCs do not stabilize emissions. Assuming the social value of a metric ton of $\mathrm{CO}_{2}$ abated is $\$ 42 \mathrm{US}$, the global climate benefit of the Agreement through 2030 is $\$ 2.25$ trillion in present value.

\section{CRediT authorship contribution statement}

Weifeng Liu: Conceptualization, Methodology, Software, Writing original draft. Warwick J. McKibbin: Conceptualization, Methodology, Software, Writing - original draft. Adele C. Morris: Conceptualization, Methodology, Writing - review \& editing. Peter J. Wilcoxen: Conceptualization, Methodology, Software, Writing - original draft. 


\section{Appendix A. NDC aggregation for G-Cubed}

Table 2 contains the targets calculated for each region in the GCubed model. The targets for OPEC and ROW depend on the G-Cubed baseline because most of OPEC countries and some of ROW countries set their NDCs relative to 2030 BAU and thus we assume the G-Cubed baseline as their BAU emissions (see more details below).

We calculate the NDC targets by making a number of assumptions. We start with the NDCs each country submitted to the UNFCCC. For each NDC,

(1) We assume that all countries targeting GHGs will reduce their energy-related $\mathrm{CO}_{2}$ proportionally to the overall scope of emissions pertinent to their targets. We do not adjust for expected changes in other GHG sources and gases, so our estimated targets may be more or less stringent than they will be in practice owing to baseline trends in non-energy sectors.

(2) We source all emissions data over the period from 1990 to 2015 from the U.S. Energy Information Administration.

(3) We target the unconditional NDCs or the least ambitious target in a range of proposed targets. If any country does not have an unconditional NDC, we assume the conditional NDC as the target.

For individual countries in the G-Cubed model, Table 3 in the text reports the NDC we calculate. Estimated targets for Australia, Japan, and the United States require only the above three assumptions. Other countries and regions involve more complicated or subjective analysis

(1) Russia expresses its NDC target relative to 1990, but Russian emissions data starts from 1992, so we substitute its 1992 data for 1990.

(2) China has a target in terms of emissions intensity of GDP, and we calculate its emissions target as follows:

(a) China aims to double its real GDP by 2020 from 2010, and the National Energy Administration of China assumes for energy consumption forecasting that Chinese GDP will grow at 5.5\% each year from 2021 to 2030.

(b) China targets to reduce its carbon intensity by $60 \%$ by 2030 relative to 2005.

(c) Given China's GDP and total $\mathrm{CO}_{2}$ emissions in 2005, we calculate China's emissions intensity in 2005 and then the target emissions intensity in 2030.

(d) Given China's GDP target, we calculate the implied emissions target in 2030.

(3) India also has a target in terms of emissions intensity of GDP, but we don't have official forecasts for GDP, so we solve in the G-Cubed model for the $\mathrm{CO}_{2}$ tax rates required to achieve the targeted emissions intensity in 2030 and obtain the projected emissions level in 2030.

(4) Europe consists of all countries in the European Union, and Norway and Switzerland. The European Union submits its NDC target as a whole. We calculate its emissions target as follows:

(a) For eight countries without emissions data in the reference year (1990) including Croatia, Estonia, Germany, Latvia, Lithuania, Slovakia, Slovenia and Switzerland, we use their earliest data for their 1990 emissions. As the earliest data for those countries are available in either 1991, 1992 or 1993, so this approximation would not have much bias.

(b) We calculate the emissions target for the European Union, Norway and Switzerland respectively, and add them up to get the target for the region.

(5) ROECD consists of three countries and each has a straightforward NDC target relative to a historical year, so we calculate the emissions target for each country and then add them up to get the target for the region.

(6) OPEC countries fall into two groups: one group has NDCs, and the other has no NDCs.

(a) All countries with NDCs set their targets relative to $2030 \mathrm{BAU}$, so we use the G-Cubed baseline emissions as their BAU emissions.

(b) We disaggregate the aggregate OPEC BAU emissions in 2030 across all countries based on their emissions shares in 2015.

(c) We calculate each country's target given their BAU emissions in 2030, and keep unchanged the emissions of those countries without NDCs, and then added them up.

(7) ROW consists of all countries that are not included in the above regions, and its target calculation is complicated.

(a) We first categorize all ROW countries into three groups:

- Type 1 - Countries that set their NDCs relative to $2030 \mathrm{BAU}$

- Type 2 - Countries that set their NDCs in levels relative to historic years;

- Type 3 - Countries that set their NDCs in terms of emissions intensity of GDP relative to historic years;

- Type 4 - Countries without NDCs.

(b) We use actual emissions in 2015 to calculate the share of each above group in total ROW emissions.

(c) We disaggregate the total 2030 emissions of ROW in the GCubed baseline for the four groups based on their shares in 2015.

(d) For Type 1 countries, we calculate their targets based on their 2030 BAU emissions.

(e) For Type 2 countries, we calculate their targets given the historical data,

(f) For Type 3 countries (Chile, Malaysia and Singapore), we have different treatments. We directly obtain an estimate of emissions for Chile from Climate Action Tracker. For Malaysia, we assume a constant growth rate of GDP (4\%) over the period from 2016 to 2030 based on its recently historical growth rates, to give an estimate for GDP in 2030, and then calculate emissions given the intensity target. We exclude Singapore from ROW because its official emissions data is not consistent with the EIA data.

(g) For Type 4 countries, we assume the BAU emissions to be their target emissions.

We add up emissions targets of the four types of countries to get the target for the region. 
Appendix B. Other studies of the Paris Agreement

Table A1

Global studies of the Paris Agreement.

\begin{tabular}{|c|c|c|}
\hline Global studies & Models & Main conclusions \\
\hline \multicolumn{3}{|c|}{ Type 1: dynamic computable general equilibrium models } \\
\hline $\begin{array}{l}\text { W. McKibbin, 2015; W } \\
\text { McKibbin, } 2015\end{array}$ & G-Cubed & $\begin{array}{l}\text { - The agreement has small negative impacts on GDP by } 2030 \text { with a loss of } 0.1 \% \text { for the U.S., } 0.02 \% \text { for Japan, } 0.2 \% \\
\text { for Europe, } 0.8 \% \text { for Canada, } 0.45 \% \text { for China, and } 0.58 \% \text { for Australia. } \\
\text { - The impacts are sensitive to the future costs of new energy technologies. }\end{array}$ \\
\hline Vandyck et al. (2016) & JRC-GEM-E3 and JRC-POLES & $\begin{array}{l}\text { - The NDC and } 2{ }^{\circ} \mathrm{C} \text { scenarios both lead to small global GDP losses }(0.42 \% \text { and } 0.72 \% \text {, respectively). } \\
\text { - The commitments of some regions are not ambitious with their targets close to or higher than their baseline } \\
\text { levels in } 2030 \text {. } \\
\text { - A substantial gap remains between the global emissions in the NDC and } 2{ }^{\circ} \mathrm{C} \text { scenarios in } 2030 \text {. } \\
\text { - The agreement has little impact on global oil and gas demand but reduces coal demand by } 15 \% \text { in } 2030 \text {. } \\
\text { - Energy demand reduction and decarbonization of power sectors are important contributors to overall emission } \\
\text { reductions. }\end{array}$ \\
\hline Fujimori et al. (2016) & AIM & $\begin{array}{l}\text { The global welfare loss of achieving NDCs in terms of consumption change in } 2030 \text { is } 0.47 \% \text { without emissions } \\
\text { trading and falls significantly to } 0.16 \% \text { with emissions trading. } \\
\text { - The global welfare loss of achieving the } 2{ }^{\circ} \mathrm{C} \text { target is } 1.4-3.4 \% \text { without emissions trading depending on } \\
\text { burden-sharing schemes and falls to } 1.4-1.7 \% \text { with emissions trading. }\end{array}$ \\
\hline Kompas et al. (2018) & Dynamic GTAP & $\begin{array}{l}\text { - The agreement slows global warming to around } 2{ }^{\circ} \mathrm{C} \text { by } 2100 \text {, while global mean temperatures could increase up } \\
\text { to } 4{ }^{\circ} \mathrm{C} \text { without any countervailing action to reduce emissions. } \\
\text { - The global GDP loss of temperature increase by } 2{ }^{\circ} \mathrm{C} \text { and } 4{ }^{\circ} \mathrm{C} \text { is around } 2 \% \text { and } 7 \% \text { in } 2100 \text {, respectively, } \\
\text { indicating that the global GDP gain of the agreement is around } 5 \% \text { in } 2100 \text {. }\end{array}$ \\
\hline Babonneau et al. (2018) & GEMINI-E3 & $\begin{array}{l}\text { - The agreement is not in line with the } 2{ }^{\circ} \mathrm{C} \text { target. } \\
\text { - The global welfare cost in terms of consumption change in } 2030 \text { is } 0.8 \% \text { without emissions trading and falls to } \\
0.3 \% \text { with emissions trading. } \\
\text { Energy exporting countries suffer the most due to loss of energy exporting revenues, and industrialized coun- } \\
\text { tries have welfare losses driven by abatement costs, while China and India have welfare gains due to limited } \\
\text { commitments and gains from terms of trade. }\end{array}$ \\
\hline
\end{tabular}

Type 2: integrated assessment models

Fawcett et al. (2015) GCAM and MAGICC

- The agreement reduces the probability of temperature change exceeding $4{ }^{\circ} \mathrm{C}$ in 2100 by $75 \%$ compared with the no-policy scenario, but it has only a chance of $8 \%$ to limit warming to $2{ }^{\circ} \mathrm{C}$.

Akimoto et al. (2017) DNE21+

- The marginal abatement cost is high for Japan and Europe ( $\$ 378$ and $\$ 210$ per ton $\mathrm{CO}_{2}$ respectively), and is close to zero for China, India, South Africa and Russia, with the U.S in the middle ( $\$ 85$ per ton $\mathrm{CO}_{2}$ ).

- The agreement is not consistent with the $2{ }^{\circ} \mathrm{C}$ goal, and the size of the gap depends on climate sensitivity.

- Abatement costs are sensitive to socio-economic assumptions.

- Among the ten major emitting economies, Brazil, Canada and the U.S. have the highest costs as share of GDP while the costs for Japan, China, Russia and India are relatively low.

- International emission trading could substantially decrease global costs by half.

- Abatement costs of achieving emissions consistent with $2{ }^{\circ} \mathrm{C}$ pathways are three times higher than the costs of NDCs.

Kaya et al. (2015) DEN21+ and MAGICC - The agreement is not on track for the $2{ }^{\circ} \mathrm{C}$ target with climate sensitivity of $3{ }^{\circ} \mathrm{C}$ but is compatible with the target with climate sensitivity of $2.5^{\circ} \mathrm{C}$.

Type 3: partial-equilibrium or reduced-form energy models Kitous and Keramidas JRC-POLES (2015)

Parry et al. (2018) A reduced-form energy model

- The agreement results in global emissions peaking in 2035 with unconditional NDCs and in 2030 with conditional NDCs, and results in a global temperature increase of around $3{ }^{\circ} \mathrm{C}$ by 2100 .

Given $\mathrm{CO}_{2}$ taxes rise linearly from $\$ 5$ per ton in 2017 to $\$ 70$ by 2030 among G20 countries, seven countries meet or exceed their commitments, six countries need further reductions of up to $10 \%$, and another six need further reductions of above $10 \%$. This dispersion reflects both differences in target stringency and price responsiveness of emissions across countries.

- The welfare costs in terms of consumer surplus changes net government revenues are less than $0.8 \%$ of GDP in 2030 in all but three countries (China, India and South Africa) whose costs are 1-1.6\% of GDP.

- The net domestic welfare gains including local environmental benefits (but not global warming) are quite large for some countries: $0.7 \%$ of GDP in Korea, $2.3 \%$ in India, 3.7\% in Russia and 6.7\% in China, suggesting that many G20 countries can move unilaterally with carbon pricing.

Type 4: model comparison

Aldy et al. (2016) Four IAMs: DNE21 +, GCAM,

- Wealthier countries pledge to undertake greater emissions reductions with higher costs. MERGE and WITCH.

- The marginal abatement costs vary across countries by two orders of magnitude, illustrating that large efficiency gains are available through joint mitigation efforts and carbon price coordination.

Rogelj et al. (2016) Eleven global studies ${ }^{\mathrm{a}}$

- There is a wide range of estimates of future emissions across studies, and four key factors contribute to the differences: incomplete coverage, uncertain projections, land-use-related emissions, and historical emissions and metrics.

- The agreement lowers emissions compared to current policies, but still implies median warming of 2.6 to $3.1{ }^{\circ} \mathrm{C}$ by 2100 .

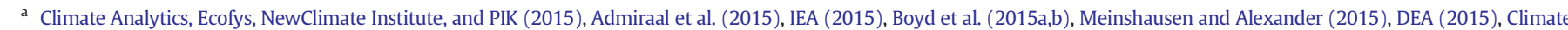
Interactive (2015), Fawcett et al. (2015), UNFCCC (2015), Kitous and Keramidas (2015), den Elzen et al. (2015). 
Table A2

Country studies of the Paris Agreement.

\begin{tabular}{|c|c|c|}
\hline Country studies & Models & Main conclusions \\
\hline \multicolumn{3}{|l|}{ United States } \\
\hline Larsen et al. (2017) & $\begin{array}{l}\text { National Energy Modeling } \\
\text { System }\end{array}$ & $\begin{array}{l}\text { - The U.S. GHG emissions would fall by } 15-19 \% \text { by } 2025 \text { under current policy, which is short of its } 26-28 \% \\
\text { commitment. } \\
\text { - The U.S. withdrawal is assessed in two scenarios: a temporary delay until } 2025 \text { and a complete stop after } 2015 \text { in } \\
\text { mitigation actions. }\end{array}$ \\
\hline Chen et al. (2018) & GCAM and MAGICC & $\begin{array}{l}\text { The probability of achieving the } 2{ }^{\circ} \mathrm{C} \text { goal would decrease by } 6-9 \% \text { even if the U.S. resumes mitigation efforts for } \\
\text { achieving its NDC after } 2025 \text {. } \\
\text { - Without U.S. participation, increased reduction efforts required for the rest of the world to achieve the } 2{ }^{\circ} \mathrm{C} \text { goal } \\
\text { result in significantly higher global cumulative mitigation costs from } 2015 \text { to } 2100 \text {. }\end{array}$ \\
\hline $\begin{array}{l}\text { Chen and Hafstead } \\
\text { (2019) }\end{array}$ & & $\begin{array}{l}\text { - Carbon taxes and economic costs of achieving the U.S. } 28 \% \text { emissions reduction by } 2025 \text { relative to } 2005 \text { are modest, } \\
\text { with a constant economy-wide carbon tax of } \$ 43 \text { starting in } 2019 \text { and a real GDP loss of } 0.45 \% \text { in } 2025 \text {. } \\
\text { Different methods of tax revenue recycling do not much affect carbon price paths, but they significantly affect the } \\
\text { costs of carbon taxes. The welfare costs (equivalent variation) of carbon taxes fall } 35 \% \text { and } 55 \% \text { under individual } \\
\text { income tax or corporate income tax cuts relative to lump-sum rebates. } \\
\text { - The delay of carbon taxes increases the tax rate required to meet the target by } 2025 \text {. The rate increases from } \$ 43 \text { to } \\
\$ 47 \text { if the policy is delayed from } 2019 \text { to } 2021 \text {, and increases to } \$ 53 \text { if the policy is delayed to } 2023 \text {. }\end{array}$ \\
\hline $\begin{array}{l}\text { McFarland et al. } \\
\text { (2018) }\end{array}$ & $\begin{array}{l}\text { Energy Modeling Forum } 32 \\
\text { (model comparison) }\end{array}$ & $\begin{array}{l}\text { - Carbon prices lead to significant reductions in } \mathrm{CO} 2 \text { emissions across all models, with the vast majority of the } \\
\text { reductions occurring in the electricity sector. } \\
\text { - Emissions reductions do not significantly depend on the rebate or tax cut used to return revenues to the economy. } \\
\text { - Economic costs in terms of either GDP or welfare are modest, but vary across models. The costs are offset by benefits } \\
\text { from avoided climate damages and health benefits from reductions in conventional air pollution. } \\
\text { - Carbon prices at } \$ 25 \text { or even lower levels cause significant shifts away from coal as an energy source with responses } \\
\text { of other energy sources highly dependent upon technology cost assumptions. } \\
\text { - } \mathrm{CO}_{2} \text { taxes must increase at a fairly high rate ( } 5 \% \text { every year) to sustain reductions in emissions. } \\
\text { - When the U.S. adopts } \mathrm{CO}_{2} \text { taxes unilaterally, international } \mathrm{CO}_{2} \text { leakage does not significantly undermine the emis- } \\
\text { sions reducing objective. }\end{array}$ \\
\hline
\end{tabular}

China

Fu et al. (2015)

McKibbin et al. G-Cubed

(2015b)

Qi et al. (2016)

Weng et al. (2018) China-in-Global-Energy Model

Parry et al., 2016 A reduced-form energy model

Timilsina et al. Dynamic CGE model of China (2018)

Liu et al. (2017) models $^{\mathrm{b}}$

Mischke and

Comparison of 18 Chinese

Karlsson (2014)

PECE, Renmin University and NCSC
Comparison of 12 global

- Carbon intensity of GDP decreases quickly in the NDC scenario from an annual rate of 3.9\% over 2005-2020 to 4.4\% over $2020-2030$, followed by $6.3 \%$ and $9.2 \%$ in the following two decades respectively.

- China faces challenges in achieving its NDC targets, including the stage of economic and social development, the economic structure, the energy structure, technological capacity, institutional and policy constraints, etc.

- Achieving China's commitment of emissions peaking in 2030 implies a substantial departure from baseline emissions, even after accounting for large baseline reductions in China's emissions intensity.

- Two policies are considered: economy-wide and electricity-sector emissions trading. Both policies operate mainly through reducing coal. The reductions are spread throughout the economy under the economy-wide trading system, while concentrated in the electricity sector under the electricity-sector trading policy.

- Both policies have similar impacts on real GDP and its components, with real GDP lower by $1.5 \%$ than the baseline in 2030.

- China's policies to control emissions have little effect on emissions elsewhere.

- The combination of low-carbon energy policies and extending emissions intensity targets through 2050 reduces emissions significantly by $43 \%$ in 2050 relative to the no-policy reference, but China's emissions still increase by over $60 \%$ between 2010 and 2050.

- China's goal of peaking emissions by 2030 requires $\mathrm{CO}_{2}$ taxes higher than $\$ 25$.

- Achieving China's commitments requires a price floor path of $\$ 4$ before 2020, \$8 between 2021 and 2025 and $\$ 12$ between 2026 and 2030.

- Among a wide range of policies, carbon and coal taxes are the most effective policies for meeting environmental and fiscal objectives as they comprehensively cover emissions and have the largest tax base.

- An increasing carbon tax that starts at a small rate in 2015 and rises to a level to meet the NDC target in 2030 would cause smaller GDP loss than the carbon tax with a constant rate would do.

- The GDP loss due to the carbon tax would be smaller when the tax revenue is utilized to cut existing distortionary taxes than when it is transferred to households as a lump-sum rebate.

- China's emissions will continue to grow until 2040-2050 and will double its 2010 level without additional policy intervention.

- The emissions estimates by 2030 vary significantly across models with the growth rate ranging from $21 \%$ to $119 \%$ in 2030 relative to 2010 , with the median value of $77 \%$.

- Peaking emissions around 2030 requires the annual emissions growth rate to be reduced by $2 \%$ below the baseline level, and the emissions reduction will largely depend on penetration of renewable energy.

- There is a wide range of estimates in the baseline: from 2010 to 2030 , GDP growth varies from $200 \%$ to $350 \%$, energy demand increase varies from $50 \%$ to $125 \%$, and carbon emissions increase varies from $50 \%$ to $100 \%$.

- The models suggest a rather gradual and long-term transition towards a low-carbon economy in China, and there is no an emissions peak or stabilization period before 2040 in the baseline.

\footnotetext{
a See the model at https://globalchange.mit.edu/publication/16001.

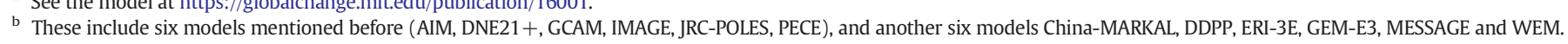
See more details in their paper.

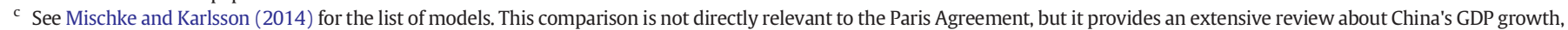
energy demand and carbon emissions over 2010-2050 based on representative Chinese economic and energy models.
} 


\section{Appendix C. Sensitivity tests}

To assess the robustness of the model's results we carried out sensitivity tests with respect to two of the model's key parameters: the fractions of households and investors who make fully forward-looking decisions. In the standard version of the model, both of these parameters are set to 0.3 meaning that $30 \%$ of each group is forward-looking and the remaining $70 \%$ are myopic. In the sensitivity tests we changed each parameter, one at a time, to 0.8 , making $80 \%$ of each group fully forward-looking. We then recomputed the model's baseline and Paris trajectory. When computing the Paris trajectories we held the carbon taxes at their values from the body of the paper; that is, we did not compute new tax rates to bring the revised trajectories into compliance with the NDCs of the regions.

Figs. C1 and C2 show the model's results for four key variables for the United States: real GDP and carbon dioxide emissions (Fig. C1) and real consumption and investment spending (Fig. C2). Each figure shows six runs: the standard baseline and Paris simulations ("Std"); a baseline and Paris simulation when the household
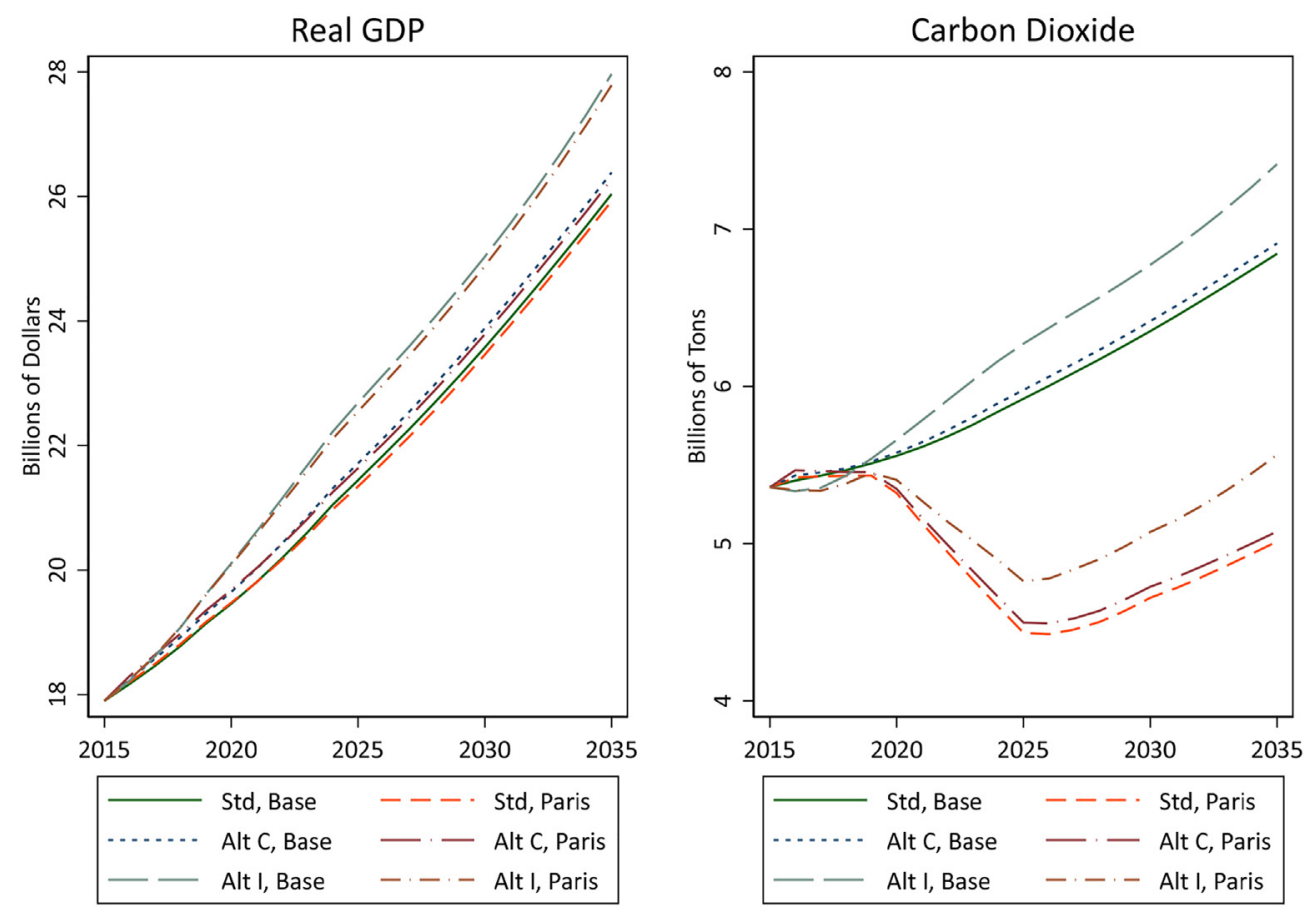

Fig. C1. Sensitivity of GDP and emissions to the degree of foresight.
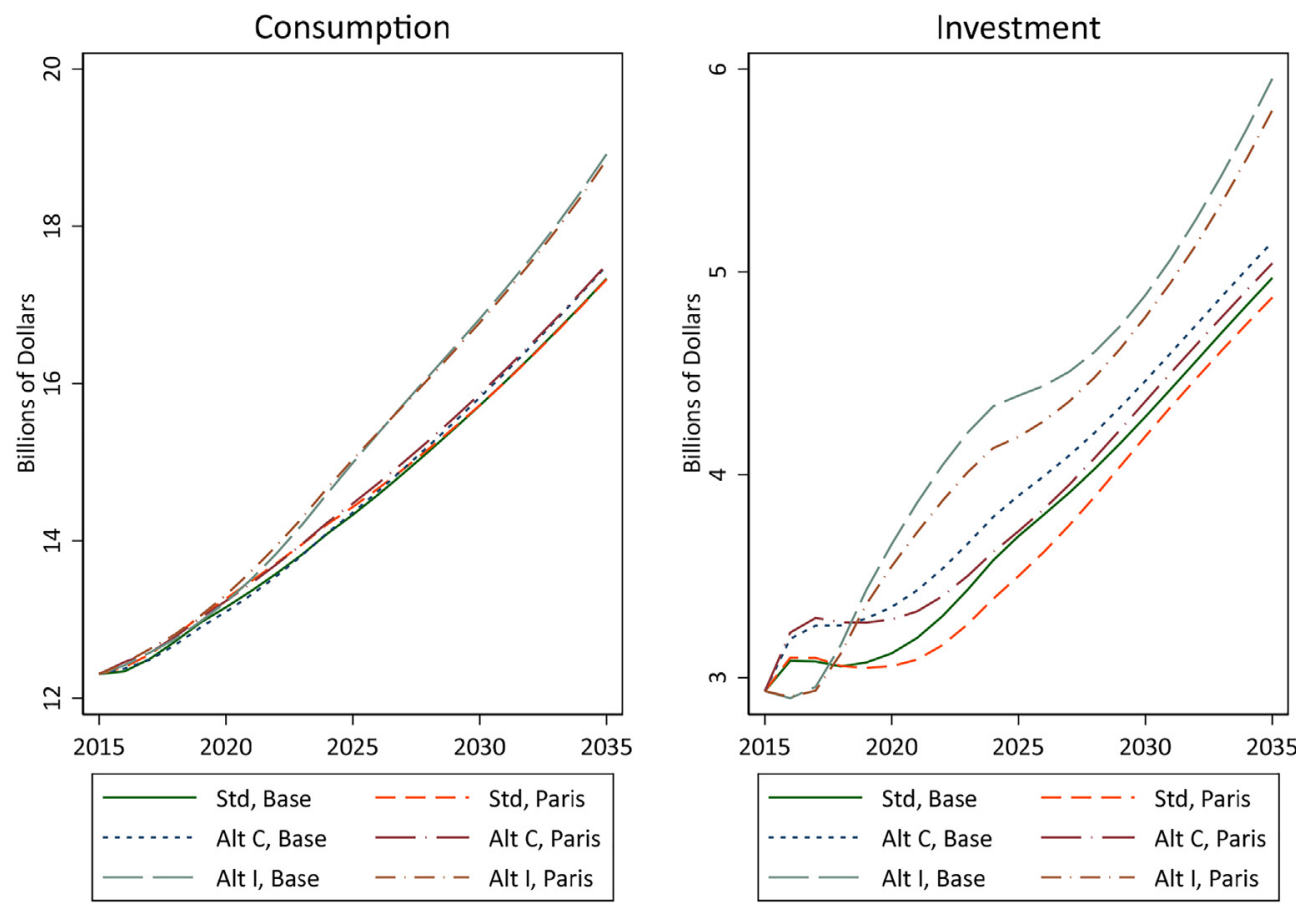

Fig. C2. Sensitivity of consumption and investment to the degree of foresight. 
foresight parameter is set to 0.8 ("Alt C"); and a baseline and Paris run with the investment foresight parameter set to 0.8 ("Alt I"). As shown by the GDP panel of Fig. C1, the parameters can have significant effects on the baseline but have little effect on the impact of the tax (the difference between the baseline and Paris trajectory). In particular, raising the degree of foresight by investors raises the baseline GDP trajectory substantially, and the Paris trajectory rises along with it. Raising the degree of foresight by consumers also raises the baseline and Paris trajectories but to a much smaller degree. In both alternative cases, the difference between the baseline and the corresponding Paris trajectory is very similar to that for the standard version of the model.

Fig. C2 narrows the focus to the two components of GDP that are most strongly affected by the foresight parameters: aggregate consumption and investment. The results for consumption again emphasize that the parameters can have significant impacts on the baseline but have little impact on the deviation between the baseline and the Paris results. Both the baseline and Paris curves are substantially higher in the long run with greater foresight by investors but in all three cases the consumption curves with and without Paris are nearly indistinguishable.

The results for investment, in the right panel of Fig. $\mathrm{C} 2$, are the most interesting. Increasing the degree of foresight by households raises baseline and Paris investment quite a bit in the near term but by 2025 the difference is small. Raising the degree of foresight by investors, in contrast, sharply lowers investment for the first few years of the simulation and then raises it substantially relative to the standard version of the model starting around 2018. That is, greater foresight by households causes them to defer consumption slightly, raising investment, while in contrast more foresight by investors causes them to defer investment. In both cases, however, the differences between the baseline and Paris trajectories are small.

In terms of welfare, raising the household foresight parameter increases the equivalent variation slightly: it goes from $0.4 \%$ of baseline wealth under the standard parameter set to $0.5 \%$. In contrast, increasing the degree of foresight by investors causes the Agreement's impact on consumption to be less favorable in the short run, and more unfavorable in the long run, than under the standard parameters. The effect is large enough to change the sign of the equivalent variation, which becomes $-0.3 \%$.

We conducted similar tests for other model parameters, including two parameters in the wage equation, the parameters governing the degree of adjustment costs in investment, the elasticities of substitution between foreign and domestic goods, the risk premium on wealth, the marginal propensity to consume out of income, and the parameters governing the rate at which non-forward-looking agents update their expectations. The foresight parameters discussed above had the largest impact on the results.

\section{References}

Admiraal, A., M. den Elzen, N. Forsell, O. Turkovska, M. Roelfsema, and H. van Soest (2015). Assessing Intended Nationally Determined Contributions to the Paris Climate Agreement - What Are the Projected Global and National Emission Levels for 2025-2030? PBL Netherlands Environmental Assessment Agency Report No. 1879. http://www.pbl.nl/sites/default/files/cms/publicaties/pbl-2015-assessing-intendednationally-determined-contributions-to-the-paris-climate-agreement_1879.pdf.

Akimoto, K., Sano, F., Tehrani, B.S., 2017. The analyses on the economic costs for achieving the nationally determined contributions and the expected global emission pathways. Evolut Inst Econ Rev (2017) 14 (1), 193-206. https://doi.org/10.1007/s40844-0160049-y.

Aldy, J., Pizer, B., Akimoto, K., 2017. Comparing emission mitigation effort. Clim. Pol. 17 (4), 501-515.

Babonneau, F., Bernard, A., Haurie, A., Vielle, M., 2018. Meta-modeling to assess the possible future of Paris Agreement. Environ. Model. Assess. 23 (6), 611-626. https:// doi.org/10.1007/s10666-018-9630-6.

Barro, R.J., 1991. Economic growth in a cross section of countries. Q. J. Econ. 106 (2), 407-443.

Barro, R.J., 2015. Convergence and modernisation. Economic Journal 125 (585), 911-942.
Barron, A. R., A. A. Fawcett, M. A. C. Hafstead, J. R. Mcfarland, and A. C. Morris (2018). Policy Insights From the EMF 32 Study On U.S. Carbon Tax Scenarios. Climate Change Economics 9(1), 2018

Boyd, R., J. Cranston Turner, and B. Ward (2015a). ESRC Centre for Climate Change Economics and Policy \& Grantham Research Institute on Climate Change and the Environment. Intended Nationally Determined Contributions: What are the Implications for Greenhouse Gas Emissions in 2030? http://www.lse.ac.uk/GranthamInstitute/ wp-content/uploads/2015/10/Boyd_Turner_and_Ward_policy_paper_October_2015. pdf.

Boyd, R., N. Stern, and B. Ward (2015b). ESRC Centre for Climate Change Economics and Policy \& Grantham Research Institute on Climate Change and the Environment. What Will Global Annual Emissions of Greenhouse Gases Be in 2030, and Will They Be Consistent with Avoiding Global Warming of More Than $2^{\circ} \mathrm{C}$ ? http://www.lse.ac.uk/ GranthamInstitute/wp-content/uploads/2015/05/Boyd_et_al_policy_paper_May_ 2015.pdf.

Chen, Y., Hafstead, M.A.C., 2019. Using a carbon tax to meet US international climate pledges. Climate Change Economics 10 (1). https://doi.org/10.1142/ S2010007819500027.

Chen, H., Wang, L., Chen, W., Luo, Y., Wang, Y., Zhou, S., 2018. The global impacts of US climate policy: a model simulation using GCAM-TU and MAGICC. Clim. Pol. 18 (7), 852-862. https://doi.org/10.1080/14693062.2018.1465390.

Climate Analytics, Ecofys, NewClimate Institute, PIK, 2015. Climate pledges will bring $2.7^{\circ} \mathrm{C}$ of warming, potential for more action. Climate Action Tracker. https:// climateactiontracker.org/publications/climate-pledges-will-bring-27c-of-warmingpotential-for-more-action/

Creutzig, Felix, He, Dongquan, 2009. Climate change mitigation and co-benefits of feasible transport demand policies in Beijing. Transp. Res. Part D: Transp. Environ. 14 (2), 120-131. https://doi.org/10.1016/j.trd.2008.11.007.

Danish Energy Agency, 2015. Analyzing the 2030 emissions gap. https://ens.dk/en/ourservices/projections-and-models/models/analyzing-2030-emissions-gap.

den Elzen, M., et al., 2015. Enhancing mitigation ambitions in the major emitting countries: analysis of current and potential climate policies. PBL Netherlands Environmental Assessment Agency Report No. 1631 http://www.pbl.nl/en/publications/ enhancing-mitigation-ambitions-inthe-major-emitting-countries-analysis-of-current-and-potential-climate-policies.

Energy Information Administration, 2018. Energy Outlook, February. US Department Energy Washington DC.

Fawcett, A.A., Iyer, G.C., Clarke, L.E., Edmonds, J.A., Hultman, N.E., McJeon, H.C., Rogelj, J., Schuler, R., Alsalam, J., Asrar, G.R., Creason, J., Jeong, M., McFarland, J., Mundra, A, Shi, W., 2015. Can Paris pledges avert severe climate change? Science 350 (2015), 1168-1169. https://doi.org/10.1126/science.aad5761.

Fu, S., J. Zou and L. Liu (2015). An Analysis of China's NDC. International Center for Climate Governance Reflection No. 36/July 2015.

Fujimori, S., Kubota, I., Dai, H., Takahashi, K., Hasegawa, T., Liu, J.-Y., Hijioka, Y., Masui, T., Takimi, M. 2016. Will international emissions trading help achieve the objectives of the Paris Agreement? Environ. Res. Lett. 11 (10). https://doi.org/10.1088/1748-9326/ $11 / 10 / 104001$.

Hof, A.F., den Elzen, M.G.J., Admiraal, A., Roelfsema, M., Gernaat, D.E.H.J., van Vuuren, D.P. 2017. Global and regional abatement costs of nationally determined contributions (NDCs) and of enhanced action to levels well below $2^{\circ} \mathrm{C}$ and $1.5^{\circ} \mathrm{C}$. Environ. Sci. Pol. 71 (2017), 30-40. https://doi.org/10.1016/j.envsci.2017.02.008.

International Energy Agency, 2015. World Energy Outlook, 2015. https://webstore.iea. org/world-energy-outlook-2015

Kaya, Y., Yamaguchi, M., Akimoto, K., 2016. The uncertainty of climate sensitivity and its implication for the Paris negotiation. Sustain Sci 11, 515-518.

Kitous, A., Keramidas, K., 2015. Analysis of scenarios integrating the NDCs. JRC policy brief. European Commission. Joint Research Centre. https://ec.europa.eu/jrc/sites/default/ files/JRC97845.pdf

Kompas, T., Pham, V.H., Che, T.N., 2018. The effects of climate change on GDP by country and the global economic gains from complying with the Paris climate accord. Earth's Future 6, 1153-1173. https://doi.org/10.1029/2018EF000922.

Larsen, K., J. Larsen, W. Herndon, S. Mohan, and T. Houser (2017). Rhodium group. Taking stock 2017: adjusting expectations for US GHG emissions. https://rhg.com/research/ taking-stock-2017-us-greenhouse-gas-emissions/.

Liu, Q., Gu, A., Teng, F., Song, R., Chen, Y., 2017. Peaking China's CO2 emissions: trends to 2030 and mitigation potential. Energies 2017 (10), 209. https://doi.org/10.3390/ en10020209.

Markandya, A., et al., 2018. Health co-benefits from air pollution and mitigation costs of the Paris Agreement: a modelling study. Lancet No. 1 (e), 126-133.

Mayrhofer, J.P., Gupta, J., 2016. The science and politics of co-benefits in climate policy. Environ. Sci. Pol. 57, 22-30.

McFarland, J. R., A. A. Fawcett, A. C. Morris, J. M. Reilly, and P. J. Wilcoxen (2018). Overview of the EMF 32 Study on U.S. Carbon Tax Scenarios. Climate Change Economics 9(1), 2018.

McKibbin, W., Wilcoxen, P., 1999. The theoretical and empirical structure of the G-cubed model. Econ. Model. 16 (1), 123-148.

McKibbin, W. and P. Wilcoxen (2013). A Global Approach to Energy and the Environment: The G-cubed Model. Handbook of CGE Modeling, Chapter 17, North Holland, pp. 995-1068.

McKibbin, W., Pearce, D., Stegman, A., 2007. Long term projections of carbon emissions. Int. J. Forecast. 23, 637-653.

McKibbin, W, 2015. Report 1: 2015 Economic Modelling of International Action Under a new Global Climate Change Agreement. Report to Department of Foreign Affairs and Trade. 
McKibbin, W., 2015. Report 2: economic modeling of Australian action under a new climate agreement. Report to Department of Foreign Affairs and Trade (20 August 2015).

McKibbin, W., Morris, A., Wilcoxen, P., 2011. Comparing climate commitments: a modelbased analysis of the Copenhagen Accord. Climate Change Economics 2 (2), 79-103.

McKibbin W., A. Morris, P. Wilcoxen, and Y. Cai (2015). Carbon Taxes and US Fiscal Reform. The National Tax Journal, Vol. 68, No. 1 March, National Tax Association, Washington DC, pp. 139-156.

McKibbin, J.W., Morris, A., Wilcoxen, P.J., Liu, W., 2015b. China's Carbon Future: A Modelbased Analysis (Brookings Institution Climate and Energy Economics Discussion Paper).

McKibbin, W.J., Morris, A., Wilcoxen, P.J., Liu, W., 2018. The role of border adjustments in a US carbon tax. Climate Change Economics 9 (1), 1-42.

Meinshausen, M., Alexander, R., 2015. NDC \& NDC factsheets. http://climatecollege. unimelb.edu.au/ndc-NDC-factsheets.

Mischke, P., Karlsson, K.B., 2014. Modeling tools to evaluate China's future energy system - a review of the Chinese perspective. Energy 69 (2014), 132-143.

Ortolano, L. (2018). Local and regional pollution reduction co-benefits from climate change mitigation interventions. IEG working paper 2018.01, World Bank, Washington, DC.

Parry, Ian W.H., Heine, Dirk, Li, Shanjun, Lis, Eliza, 2014. Getting Energy Prices Right: From Principle to Practice. International Monetary Fund, Washington, DC.

Parry, I., Chandara Veung, W.H., Heine, D., 2015. How much carbon pricing is in countries' own interests? The critical role of co-benefits. Climate Change Economics 6 (4).

Parry, I., B. Shang, P. Wingender, N. Vernon, and T. Narasimhan (2016). Climate Mitigation in China: Which Policies Are Most Effective? IMF Working Paper 16/148.

Parry, I., Mylonas, V., Vernon, N., 2018. Mitigation policies for the Paris Agreement: an assessment for G20 countries. IMF Working Paper 18/193. International Monetary Fund, Washington DC.
Qi, T., Winchester, N., Karplus, V.J., Zhang, D., Zhang, X., 2016. An analysis of China's climate policy using the China-in-global energy model. Econ. Model. 52, 650-660. https://doi.org/10.1016/j.econmod.2015.09.036.

Rogelj, J., den Elzen, M., Höhne, N., Fransen, T., Fekete, H., Winkler, H., Meinshausen, M. 2016. Paris Agreement climate proposals need a boost to keep warming well below $2^{\circ} \mathrm{C}$. Nature 534 (7609), 631-639. https://doi.org/10.1038/nature18307.

Stegman, A. and W. McKibbin (2013). Long Term Projections of the World Economy: A Review. CAMA Working Paper 14/2013.

Timilsina, G.R., Cao, J., Ho, M., 2018. Carbon tax for achieving China's NDC: simulations of some design features using a CGE model. Climate Change Economics 9 (3). https:// doi.org/10.1142/S2010007818500069.

UNFCCC, 2015. Synthesis report on the aggregate effect of the intended nationally determined contributions. Report No. FCCC/CP/2015/7. https://unfccc.int/resource/docs/ 2015/cop21/eng/07.pdf.

Vandyck, T. Keramidas, K, Saveyn, B, Kitous, A, Vrontisi, Z, 2016. A global stocktake of the Paris pledges: implications for energy systems and economy. Glob. Environ. Chang. 2016 (41), 46-63. https://doi.org/10.1016/j.gloenvcha.2016.08.006.

Vandyck, Toon, et al., 2018. Air quality co-benefits for human health and agriculture counterbalance costs to meet Paris Agreement pledges. Nat. Commun. 9 (1), 1-11. https:// doi.org/10.1038/s41467-018-06885-9.

Weng, Y., Zhang, D., Lu, L., Zhang, X., 2018. A general equilibrium analysis of floor prices for China's national carbon emissions trading system. Clim. Pol. 18, 60-70. https:// doi.org/10.1080/14693062.2018.1464895.

Xie, Y., et al., 2018. Co-benefits of climate mitigation on air quality and human health in Asian countries. Environ. Int. 119, 309-318. https://doi.org/10.1016/j.envint. 2018.07.008. 